\title{
Is Global Social Welfare Increasing? a Critical-Level Enquiry
}

John Cockburn

Jean-Yves Duclos

Agnès Zabsonré

juin / june 2014 


\section{Abstract}

We assess whether global social welfare has improved in the last decades despite (or because of) the substantial increase in global population. We use for this purpose a relatively unknown but simple and attractive social evaluation approach called criticallevel generalized utilitarianism (CLGU). CLGU posits that social welfare increases with population size if and only if the new lives come with a level of living standards higher than that of a critical level. Despite its attractiveness, CLGU poses a number of practical difficulties that may explain why the literature has left it largely unexplored. We address these difficulties by developing new procedures for making partial CLGU orderings. The headline result is that we can robustly conclude that world welfare has increased between 1990 and 2005 if we judge that lives with per capita yearly consumption of more than $\$ 1,248$ necessarily increase social welfare; the same conclusion applies to Sub-Saharan Africa if and only if we are willing to make that same judgement for lives with any level of per capita yearly consumption above $\$ 147$. Otherwise, some of the admissible CLGU functions will judge the last two decades' increase in global population size to have lowered global social welfare.

Mots-clés : Global welfare, Critical-level generalized utilitarianism, Social evaluation, Welfare dominance, Critical level, Population growth

Classification JEL : D31, D63, 132, O15, Q56

Cockburn: Département d'économique, PEP and CIRPÉE, Université Laval, Canada jcoc@ecn.ulaval.ca

Duclos: Département d'économique, PEP, CIRPÉE, Université Laval, Canada and FERDI jyves@ecn.ulaval.ca

Zabsonré: zabagnes@yahoo.fr

This work was carried out with support from SSHRC, FRQSC and the Partnership for Economic Policy (PEP), which is financed by the Department for International Development (DFID) of the United Kingdom (or UK Aid) and the Government of Canada through the International Development Research Center (IDRC). We are grateful to Araar Abdelkrim, Sami Bibi, Guillermo Cruces, Patrick Guillaumont, Pramila Krishnan, Paul Makdissi, Larry Samuelson, Leif Wenar, two anonymous referees and to participants at various seminars for useful comments and advice. 


\section{Introduction}

It took roughly 250,000 years for humanity to reach 250 million individuals - viz, at around $1 \mathrm{AD}$. It took another 1,800 years for the global population to reach 1 billion. Between 1800 and 1960, that level grew to 3 billion. The estimated global population size reached 7 billion at the turn of 2011-2012 (see United Nations 2011); current 2020 projections of the size of humanity stand at about 7.6 billion. These increases in global population sizes have been a frequent source of concern. Such concerns feed mainly on the Malthusian preoccupation that large populations can put unsustainable pressure on limited natural resources and fixed assets such as land (see for instance Ehrlich and Ehrlich 1990, Cohen 1995, Dasgupta 2010 and Eastin, Grundmann, and Prakash 2011), although it has been conversely argued that population growth can also serve as a vehicle for economic development by stimulating human ingenuity and technological progress and improving the effectiveness of the provision of public goods (see for instance Klasen and Nestmann 2006 for numerous references to the literature and Nerlove, Razin, and Sadka 1986 for a model of the overall trade-off).

While it is certainly useful to analyze population growth and living standards from a causal perspective (as has often been done: see Cassen 1994 and Birdsall, Kelley, and Sinding 2003 for a review), it would seem equally important to assess the joint normative effect of demographic growth and living standards on the value of societies. It is indeed such a normative assessment that should presumably guide demographic and development policies. A normative assessment of the joint impact of population sizes and living standards on societies raises fundamental ethical issues, however, and those issues have been somewhat neglected in the recent debates on global trends in welfare and poverty. It is our main objective in this paper to address them in a simple, original and (we believe) persuasive normative setting.

There are two major existing normative measures of the impact of population growth and living standards on social welfare. Both of them incorporate an implicit trade-off between the "quantity" and the "quality" of lives (the quality of lives being measured by their well-being, their utility, or their living standard - as in the case of our empirical application below). They derive from the standard social evaluation approaches consisting of total and average utilitarianism.

Total (or classical) utilitarianism is the oldest form of utilitarianism. It values society's welfare by the sum of utilities and thus sets the government's objective function to the "greatest happiness of the greatest number" (in the words of the total utilitarians, see Burns and Hart 2000, p. 393). The implications of total utilitarianism are clear: the quantity of lives can compensate for the quality of them. It has been convincingly argued, however, that this can lead to a "repugnant" trade-off, a term used in Parfit (1984)'s famous "repugnant conclusion”. Parfit considers as a repugnant implication of total utilitarianism the fact that any sufficiently large population, even with a very low level of average utility, could be deemed preferable to any other smaller population 
with a relatively high level of average utility ${ }^{1}$ :

"For any possible population of at least ten billion people, all with a very high quality of life, there must be some much larger imaginable population whose existence, if other things are equal, would be better, even though its members have lives who are barely worth living." (Parfit 1984, p. 388).

A revised version of utilitarianism that avoids the repugnant conclusion is average utilitarianism. Edgeworth (1925) attributes it to John Stuart Mill, who indeed chose it to justify limits to population sizes, ${ }^{2}$ although Say, Sismondi and Wicksell were probably earlier users of an average principle in the discussion of an optimal population size (see Guillaumont 1964, Sumner 1978 and Blackorby and Donaldson 1984). Average utilitarianism, however, also has "repugnant" implications. A policy designed on average utilitarianism will seek to maximize average utility, regardless of how small population size may result. A population with only a few individuals may be preferred to an arbitrarily larger one with almost the same average well-being. ${ }^{3}$ The death of a person with below-average utility (as in the case of a relatively poor person) will increase social welfare (see Cowen 1989, Broome 1992a and Kanbur and Mukherjee 2007). The replication of a population with no effect on average utility would also be a matter of social indifference.

Average utilitarianism can also lead to important (and sometimes disturbing) population policy implications. Take for instance China's 1979 implementation of the one-child policy, which has probably contributed to the remarkable increase in China's average living standards over the last three decades (see Hasan 2010 and Bussolo, De Hoyos, Medvedev, and van der Mensbrugghe 2010 for references and some evidence). The one-child policy has, however, caused an important reduction in population growth and contributed to levels of (sometimes forced) abortions of the order of 10 million per year. ${ }^{4}$ Such effects on population size would, however, not be accounted for (at least directly) by average utilitarianism. ${ }^{5}$

\footnotetext{
${ }^{1}$ See Arrhenius (2011) for a discussion of how considerations of weaker formulations of the repugnant conclusion also generate difficulties when comparing populations of different sizes.

2"It is no accident that the average theory was devised strictly to handle questions of population" (Sumner 1978, p. 99).

3"An alternative with a population of any size in which each person is equally well off is ranked as worse than an alternative in which a single person experiences a trivially higher utility level" (Blackorby, Bossert, and Donaldson 2005, p. 143). Also consider the following recently estimated impact of AIDS on the distribution of income in Côte d'Ivoire: "We find that although the size of the economy in terms of total household income is reduced by about $6 \%$ after 15 years, average household income per capita, household income inequality and poverty remain almost unchanged" (Cogneau and Grimm 2008, p. 688). According to average utilitarianism, AIDS would then have had no effect on Côte d'Ivoire's social welfare.

${ }^{4}$ See http://www.tldm.org/News13/13MillionAbortionsPerYearInChina.htm. One outcome of this trade-off between the quantity and the quality of lives is that abortions of female fetuses are more common in China and elsewhere, largely explained by the perceived higher (private) cost/benefit ratio of raising a daughter - see Sen (2001) for a discussion. Klasen and Wink (2003) estimate for instance the number of "missing women" in the 1990s at nearly 41 million for China and 31 million for India.

${ }^{5}$ Policies aimed at producing the "greatest happiness" can be deemed ethically unacceptable for reasons of pro-
} 
Choosing one of these two measures of social evaluation is certainly difficult, and cannot be expected to generate consensus. We can, however, address the underlying fundamental trade-offs between the quantity and the quality of lives that these measures capture through the critical-level generalized utilitarianism (CLGU) framework proposed by Blackorby and Donaldson (1984). This framework has the advantage of being both an alternative and a generalization of the above more traditional social evaluation frameworks - see page 5 for more details on this.

CLGU functions are defined as the aggregation of the differences between individual welfare (or utility) and the welfare of someone with an income level equal to a critical level. The critical level is the minimum income needed for someone to add to social welfare. CLGU can thus serve to assess the impact on social welfare of adding a new life to an existing population. CLGU functions can also be expressed as the product of population size and the difference between average welfare and welfare at the critical level. CLGU thus provides an explicit framework for trading off average welfare and population size. Choosing a relatively high value of the critical level results in optimally smaller populations; choosing a lower value results in optimally larger populations.

Despite its attractiveness, CLGU poses important practical difficulties, which have impeded its application and explained in large part its relative lack of popularity. The most salient of these are the choice of an individual welfare aggregation function and the assignment of a value to the critical level. It is indeed difficult to agree on one precise form of a CLGU function. It is also difficult to agree on the appropriate value of the critical level. The level has to be high enough to avoid the repugnant conclusion; the level also has to be low enough not to rule out additions of lives that are worth living. In a world of heterogeneous normative preferences and opinions, it is naturally difficult to envisage a wide consensus on something as fundamentally un-consensual as the precise value of living.

Our first main objective in this paper is hence to address these difficulties by deriving procedures for making partial social orderings over classes of CLGU functions. These orderings are designed to be robust to choices of individual welfare functions (within certain classes of such functions) and to ranges of the critical level.

In addition to being useful in themselves, these orderings resonate very well with an important aspect of recent debates on the evolution of global poverty. Consider for instance the following extract from Angus Deaton's 2010 presidential address to the American Economic Association (using a poverty line of $\$ 1.25$ per person per day in 2005 international dollars):

"[The figures] show the well-known reduction in the global headcount ratio, from 51.9 percent of the world's population in 1981 to 25.2 percent in 2005. In spite of growth

cedural justice (justice of means), as opposed to reasons of consequential justice (justice of outcomes, such as the achievement of greater average or total utility) — see for instance Rawls (1971). The judgements of procedural justice and consequential justice may also overlap, as in the case of forced contraception, infanticides, abortion and forced migration. We focus in this paper solely on assessments of consequential justice. 
in the world's population, the number of people in this kind of poverty has fallen by more than half a billion in the last quarter century. Much of this success comes from China, in the East Asia and Pacific region. The headcount ratio in sub-Saharan Africa has fallen only slowly, and there are 176 million more Africans in poverty in 2005 than in 1981. South Asia, dominated by India, is part success and part failure, and the Bank - and the government of India - estimate that, in spite of a falling headcount ratio, there has been a small increase in the numbers of Indians in poverty since 1981, in spite of India's relatively rapid growth in per capita GDP in recent years, and its relatively slow rate of population growth.” (Deaton 2010, p. 8)

Opposite movements of absolute and relative numbers of the poor emerge often in poverty comparisons. And when the numbers move in the same direction, they often do so at very different rates. This leads to a natural question: "If the absolute number of poor people goes up, but the fraction of people in poverty comes down, has poverty gone up or gone down?" (Kanbur 2005, p. 228 and Mukherjee 2008, p. 97; see also Chakravarty, Kanbur, and Mukherjee 2006 and Pogge 2005.) Whether we should consider absolute (total population) indices or proportional (relative to total population size) indices to measure poverty would therefore seem important. Our second main objective in this paper is to show how this important question can be nicely associated to the resolution of the equally important inquiry into the value of societies.

Our third main objective is to use CLGU to assess empirically whether there has been an improvement in social welfare during the last decades. To do this, we compare global social welfare between 1990 and 2005 from a national, regional and global perspective. We consider 173 countries (accounting for 95 percent of the global population in 2005), of which 114 are developing countries and 59 are high-income countries.

The most general result is that humanity in 2005 can be robustly considered to be better than in 1990 if we are willing to judge that lives with per capita yearly consumption of any level greater than \$1,248 necessarily increase global social welfare. For some countries and groups of countries, particularly in Europe, Central Asia and in Sub-Saharan Africa, 1990 can conversely be deemed better than 2005 if we judge that lives with per capita yearly consumption lower than $\$ 560$ necessarily decrease global social welfare - that threshold falls to $\$ 300$ for higher orders of CLGU dominance. Further regional and national comparisons illustrate how the trade-off between the quantity and the quality of lives is starker in some environments than in others. The results also demonstrate how a critical level framework assesses global social welfare differently from the traditional average and total utilitarian approaches.

The rest of the paper runs as follows. Section 2 sets the basic CLGU analytical framework. Section 3 outlines the estimation procedures. Section 4 describes the data and presents the findings. Section 5 concludes briefly. 


\section{Social evaluations when population sizes differ}

Consider two populations of different sizes. The smaller population of size $M$ has a vector $\mathbf{u}$ of individual incomes (as a shorthand for well-being, living standards, or consumption) and the larger population with vector $\mathbf{v}$ is of size $N$, with $M<N$. Let $\mathbf{u}:=\left(u_{1}, u_{2}, \ldots, u_{M}\right)$, where $u_{i}$ refers to the income of individual $i$, and $\mathbf{v}:=\left(v_{1}, v_{2}, \ldots, v_{N}\right)$, where $v_{j}$ is the income of individual $j$. To assess the value of the two populations, we let the social evaluation functions of $\mathbf{u}$ and $\mathbf{v}$ take the form

$$
W(\mathbf{u} ; \alpha)=\sum_{i=1}^{M}\left(g\left(u_{i}\right)-g(\alpha)\right)
$$

and

$$
W(\mathbf{v} ; \alpha)=\sum_{j=1}^{N}\left(g\left(v_{j}\right)-g(\alpha)\right),
$$

where $g$ is some increasing monotonic transformation of incomes over a specified interval and $\alpha$ is the critical level. The smaller population is socially better than the larger one if and only if $W(\mathbf{u} ; \alpha) \geq W(\mathbf{v} ; \alpha)$. It is clear from the above that the social value of a population remains unchanged if a new individual with income equal to $\alpha$ is added; such a social value then satisfies the critical-level population principle. Note that the framework is general enough to allow for the addition of a person to change the distribution of other individuals' incomes, absolutely and relatively speaking.

By aggregating the differences between transformations of individual incomes and of a critical level, CLGU can avoid the above-mentioned problems of both average and total utilitarianism. The addition of a new person will be socially profitable if that person's income is higher than the critical level, even though that income may not necessarily be higher than average income and so his utility may be lower than average utility. Parfit's "repugnant conclusion" is avoided since it is socially undesirable to add individuals with incomes lower than the critical level, regardless of how many there may be of them. CLGU leads to total utilitarianism when $g(\alpha)=0$. CLGU leads to average utilitarianism when "the critical level equals the maximum possible average (over persons) utility in all relevant social states" (Ng 1986, pp. 375-376); this is because CLGU then reaches its maximum at zero with the population displaying the highest level of average utility. (Larger values of the critical level may mean a preference for smaller populations even though these smaller populations may exhibit a lower level of average utility.) Other values of the critical level may lead CLGU to prefer distributions that are not found preferable by average and total utilitarianism (as we will observe empirically in the illustration below).

The critical level is clearly a central feature of the CLGU evaluation framework. It is called the "value of living" by Broome (1992b). It is described as follows in Trannoy and Weymark (2009): 
"The critical level is the level of income for which it is a matter of social indifference to add an additional person with this amount of income. For most societies, this level will be below the observed average income of the population. It is also likely to be below what is regarded as an appropriate value for an absolute poverty line". (p. 277)

Why societies should use such a level for social evaluation purposes is also suggested in John Stuart Mill's classical essay On Liberty:

"The fact itself, of causing the existence of a human being, is one of the most responsible actions in the range of human life. To undertake this responsibility - to bestow a life which may be either a curse or a blessing - unless the being on whom it is to be bestowed will have at least the ordinary chances of a desirable existence, is a crime against that being." (Mill 1859 (1962), p. 242) ${ }^{6}$

Now consider $\mathbf{u}_{\alpha}:=(\mathbf{u}, \alpha, \ldots, \alpha)$ as the vector $\mathbf{u}$ expanded to size of population $\mathbf{v}$ by adding $N-M \alpha$ 's to u. Denoting the poverty line by $z$, define the well-known FGT (Foster, Greer, and Thorbecke 1984) poverty indices of parameter $s(s \geq 1)$ for the population $\mathbf{u}$ as

$$
P^{s}(\mathbf{u} ; z)=M^{-1}\left(\sum_{i=1}^{M}\left(z-u_{i}\right)^{s-1} I\left(u_{i} \leq z\right)\right) .
$$

$I(\cdot)$ is an indicator function that takes value 1 if its argument is true and 0 if not. We use the convention that $0^{0}=1$. The FGT indices for the expanded population $\mathbf{u}_{\alpha}$ are given by

$$
P^{s}\left(\mathbf{u}_{\alpha} ; z\right)=N^{-1}\left(\sum_{i=1}^{M}\left(z-u_{i}\right)^{s-1} I\left(u_{i} \leq z\right)+(N-M)(z-\alpha)^{s-1} I(\alpha \leq z)\right) \text {. }
$$

Note that the FGT of the expanded population,

$$
P^{s}\left(\mathbf{u}_{\alpha} ; z\right)=\frac{M}{N} P^{s}(\mathbf{u} ; z)+\left(1-\frac{M}{N}\right)(z-\alpha)^{s-1} I(\alpha \leq z)
$$

is a weighted average of the usual proportional FGT for the smaller population $\mathbf{u}$ and of the FGT for its expansion, $(z-\alpha)^{s-1}$. Note that $\alpha$ helps determine the contribution of the "new lives" to

\footnotetext{
${ }^{6}$ Related to this is the analogous notion of a "restricted life" in Kavka (1982):

"The vexed problem of whether average or total utility maximization is the appropriate goal remains unsolved. (...) One approach to evaluating the desirability of states of society seems especially promising, in the present context. Let us introduce the notion of a restricted life, a life that is significantly deficient in one or more of the major respects that generally make human lives valuable and worth living. (...) Now, suppose that we adopt the principle that, other things being equal, conditions of society or the world are intrinsically undesirable from a moral point of view to the extent that they involve people living restricted lives." (pp. 104-105)
} 
social welfare; the poverty line (or censoring point) $z$ helps define the contribution of "all lives" to poverty. Under CLGU (see (1)), the larger population $\mathbf{u}_{\alpha}$ - with an additional set of people all living at the critical level $\alpha$ - has the same level of welfare as the smaller one $\mathbf{u}$; it is in this sense that when comparing a larger population to a smaller one, the "right thing to do" according to CLGU is to add hypothetical people with standard of living $\alpha$ to the smaller population. But the poverty measures (3) and (4) do differ, indicating again the difference between CLGU and poverty. ${ }^{7}$ For $s=1$, we have:

$$
N P^{s}\left(\mathbf{u}_{\alpha} ; z\right)=M P^{s}(\mathbf{u} ; z)+(N-M) I(\alpha \leq z)
$$

which is the total poverty headcount in $\mathbf{u}$ plus the increase in population size, if $z \geq \alpha$.

Similarly, the FGT index for vector $\mathbf{v}$ is defined as

$$
P^{s}(\mathbf{v} ; z)=N^{-1} \sum_{j=1}^{N}\left(z-v_{j}\right)^{s-1} I\left(v_{j} \leq z\right)
$$

The greater the value of $P_{\mathbf{v}}^{s}(z)$, the lower the social value of $\mathbf{v}$. We will see shortly that comparing $P^{s}\left(\mathbf{u}_{\alpha} ; z\right)$ and $P^{s}(\mathbf{v} ; z)$ will enable us to rank the two populations in a robust CLGU framework.

One difficulty with (1) and (2) is choosing the form that $g$ should take. We tackle this by considering classes of $g$ functions. These classes are defined with respect to conditions of order $s$. Consider $\mathcal{C}^{s}$ as the class of functions $\mathbb{R} \longrightarrow \mathbb{R}$ that are $s$-times piecewise differentiable and let $\mathcal{F}^{s}$ be defined ${ }^{8}$ as

$$
\mathcal{F}^{s}:=\left\{g \in \mathcal{C}^{s} \mid(-1)^{k} \frac{d^{k} g(x)}{d x^{k}} \leq 0 \forall k=1, \ldots, s .\right\}
$$

Also denote $W_{\alpha}^{s}$ as the class of CLGU functions with $g \in \mathcal{F}^{s}$ and critical level $\alpha$. For any vector of income $\mathbf{x} \in \mathbb{R}^{T}, T \in\{1,2,3, \ldots\}$, this class is formally defined as

$$
W_{\alpha}^{s}:=\left\{W \mid W(\mathbf{x} ; \alpha)=\sum_{k=1}^{T}\left(g\left(x_{k}\right)-g(\alpha)\right) \text { where } g \in \mathcal{F}^{s} \text { and } \mathbf{x} \in \mathbb{R}^{T}\right\} \text {. }
$$

The assumptions made on $g$ and its derivatives enable us to have social evaluation measures that

\footnotetext{
${ }^{7} \mathrm{An}$ analogous distinction between welfare and poverty arose in a lively online debate of The Economist, entitled "Too many people? This house believes that the world would be better off with fewer people". (The debate took place between August 21st 2009 and September 2nd 2009; the contributions can be found at http://www.economist.com/debate/debates/archive/page:10.) One contributor (Arturo Barrios) answered as follows:
}

"So unlike the Economist reader elites who, having solved most of their existential problems, are constantly seeking problems to temper their well-being, most people in the third world are very happy to exist indeed, thank you very much. Being poor does not make one as unhappy as the Western elites imagine".

\footnotetext{
${ }^{8}$ Note that the framework can be enlarged to consider the use of classes of "restricted" social welfare functions; details can be found in a (lengthier) working paper version of this article, Cockburn, Duclos, and Zabsonré (2011).
} 
are sensitive to income disparities. The first-order class $W_{\alpha}^{1}$ uses non-decreasing functions $g$ (see fourth line of (8)) for which an increase in any individual's income must (weakly) increase social welfare. The evaluation functions that are part of this class thus obey the (weak) Pareto principle in addition to being symmetric in income (since the form of $g$ does not depend on $i$. The secondorder class of indices must in addition obey (weakly) the Pigou-Dalton principle of transfers, which postulates that a mean-preserving transfer of income from a higher-income person to a lower-income person constitutes a (weakly speaking) social improvement. This also corresponds to the familiar incorporation of inequality aversion into social evaluations, here expressed through the weak concavity of the $g$ function in the fourth line of (8).

Social evaluation functions that are part of the third-order class of evaluation functions must also be sensitive to favorable composite transfers. These transfers are such that a beneficial PigouDalton transfer within the lower part of the distribution, coupled with an adverse Pigou-Dalton transfer within the upper part of the distribution, will weakly increase social welfare, provided that the variance of the distribution is not increased - see Kolm (1976), Kakwani (1980), Davies and Hoy (1994) and Shorrocks and Foster (1987) for formal characterizations of this transfer principle). Higher-order indices can be interpreted using the generalized transfer principles of Fishburn and Willig (1984). Fourth-order social evaluation functions, for instance, increase following a combination of a favorable composite transfer within a lower part of the distribution and of an unfavorable one within a higher part of the distribution. Generalized higher-order transfer principles essentially postulate that, as $s$ increases, social evaluation functions become increasingly Rawlsian (Blackorby and Donaldson 1978).

Now define the partial CLGU ordering $\sim_{\alpha} W$ by

$$
\mathbf{u} \succsim_{\alpha}^{s W} \mathbf{v} \Leftrightarrow W(\mathbf{u} ; \alpha) \geq W(\mathbf{v} ; \alpha) \forall W \in W_{\alpha}^{s} .
$$

This says that $\mathbf{u}$ is better than $\mathbf{v}$ if and only if $W(\mathbf{u} ; \alpha)$ is larger than $W(\mathbf{v} ; \alpha)$ for all $W$ functions in $W_{\alpha}^{s}$. Also denote by $\succsim^{s P}$ the partial FGT poverty ordering defined by

$$
\mathbf{u}_{\alpha} \succsim^{s P} \mathbf{v} \Leftrightarrow P^{s}\left(\mathbf{u}_{\alpha} ; z\right)-P^{s}(\mathbf{v} ; z) \leq 0 \text { for all } z \text {. }
$$

This says that $\mathbf{u}_{\alpha}$ is better than $\mathbf{v}$ if and only if $P^{s}\left(\mathbf{u}_{\alpha} ; z\right)$ is lower than $P^{s}(\mathbf{v} ; z)$ for all $z$. The partial orderings $\precsim_{\alpha}^{s W}$ and $\precsim P$ can be defined in the same manner as the inverse of the orderings $\succsim_{\alpha} W$ and $\succsim^{s P}$, respectively. Formally, we have that

$$
\mathbf{u} \precsim_{\alpha}^{s W} \mathbf{v} \Leftrightarrow W(\mathbf{u} ; \alpha) \leq W(\mathbf{v} ; \alpha) \forall W \in W_{\alpha}^{s}
$$

and

$$
\mathbf{u}_{\alpha} \precsim^{s P} \mathbf{v} \Leftrightarrow P^{s}\left(\mathbf{u}_{\alpha} ; z\right)-P^{s}(\mathbf{v} ; z) \geq 0 \text { for all } z \text {. }
$$


It can be demonstrated (following Foster and Shorrocks 1988 for instance) that the two partial dominance orderings $\succsim s W$ and ${ }^{s P}$ are equivalent, for some given value of the critical level $\alpha$ :

$$
\mathbf{u} \succsim_{\alpha}^{s W} \mathbf{v} \Leftrightarrow \mathbf{u}_{\alpha} \succsim^{s P} \mathbf{v}
$$

The two partial orderings $\precsim_{\alpha} W$ and $\precsim s P$ are also analogously equivalent:

$$
\mathbf{u} \precsim s W \mathbf{v} \Leftrightarrow \mathbf{u}_{\alpha} \precsim s P \mathbf{v} .
$$

These equivalence results have a number of useful properties. First, they address explicitly the link between total poverty and the value of societies. Take (14) for instance. It says that, for the larger population to dominate the smaller one (over all CLGU functions with critical level set to $\alpha$ ), total poverty in the larger population must be smaller than in the smaller population, when the smaller population is expanded with $N-M$ individuals of incomes $\alpha$. This dominance condition thus demands that total poverty must be lower in the larger population than in the non-expanded smaller population over all possible poverty lines $z$. Population size increases must therefore be combined with sufficient falls in proportional poverty for social welfare to rise.

When $s=1$, which corresponds to the most robust CLGU orderings, this means that the total number of the poor must fall over some range of poverty lines $z \in[0, \alpha]$ for population size increases to lead to greater social welfare. Otherwise, some first-order CLGU indices will necessarily declare the smaller population to be better. A similar comment applies to higher values of $s$, simply by replacing the total number of the poor by the total amount of FGT poverty.

When the $P^{s}\left(\mathbf{u}_{\alpha} ; z\right) \geq P^{s}(\mathbf{v} ; z)$ condition in (13) is checked for $z>\alpha$, it is total poverty in u's expanded population that must be compared. In this case, for $s=1$, it suffices that the total number of the poor in the smaller (expanded) population be larger than the total number of the poor in the larger population, for the larger population to dominate — recall (6). For higher values of $s$, lower proportional poverty is not sufficient for the larger population to dominate: in (5), the FGT of the expanded population may be lower than the usual proportional FGT for the smaller population.

Linking social welfare and total/proportional poverty is also interesting from the converse perspective of establishing dominance of the smaller population. From (5), it is clear that it is not enough that proportional poverty be lower in the smaller population for this to happen. For $s=1$ for instance, (6) says that it is not enough that the proportional poverty headcount - and thus that the total number of the poor - be larger in the larger population for the smaller population to dominate. It must also be that the cost of the $N-M$ additional lives in the larger population be large enough. This cost will be large if the $(z-\alpha)^{s-1} I(\alpha \leq z)$ term in (5) is low.

Alternatively, (5) can be understood as the weighted average of the poverty cost of the smaller population (measured in a total FGT fashion) and of the opportunity cost of having a lower popu- 
lation (measured by total FGT with incomes set to $\alpha$ ). (5) is therefore a weighted average of the value (here measured negatively as a cost) of the quality and of the quantity of lives. It says that the smaller population will dominate if its higher quality of lives is sufficient to offset its lower quantity of them.

A simple numerical example may help demonstrate the above procedures. Let $\mathbf{u}=(4,10,16)$ and $\mathbf{v}=(4,4,8,10,16)$. For all $z, \mathbf{v}$ has more poverty than $\mathbf{u}$, both as a fraction of the population and in terms of the total number of the poor. To see how they compare in terms of CLGU, first set $\alpha=4$; this gives $\mathbf{u}_{4}=(4,4,4,10,16)$. Whatever choice of $z, \mathbf{u}_{4}$ has more total poverty than $\mathbf{v}$; by (15), $\mathbf{v}$ has therefore robustly greater CLGU social welfare than $\mathbf{u}$ when $\alpha=4$. Now set instead $\alpha=8$. $\mathbf{u}_{8}$ then has less total poverty than $\mathbf{v}$ for any value of $z$. By (14), $\mathbf{v}$ has therefore less CLGU social welfare than $\mathbf{u}$ with $\alpha=8$; the increase in the critical level has tilted the balance in favor of the smaller population.

The equivalence results can also serve to show the tension that exists between total and average utilitarianism, and how CLGU helps ease such a tension, but also how CLGU cannot be viewed as a middle view between the two traditional approaches. To see this, consider the following decomposition of the difference between the FGT dominance curves:

$$
\begin{array}{r}
P^{s}\left(\mathbf{u}_{\alpha} ; z\right)-P^{s}(\mathbf{v} ; z)=\frac{M}{N}\{\underbrace{\left(P^{s}(\mathbf{u} ; z)-P^{s}(\mathbf{v} ; z)\right)}_{\text {proportional effect }}+\underbrace{\left(\frac{M-N}{M}\right) P^{s}(\mathbf{v} ; z)}_{\text {size effect }}\} \\
+\left(1-\frac{M}{N}\right) \underbrace{\left\{(z-\alpha)^{s-1} I(\alpha \leq z)\right\}}_{\text {critical level effect }} .
\end{array}
$$

Again, the combination of (16) and (17) is a weighted average of the value of population quality and quantity. Total and average utilitarianism clash when the quantity of lives varies. The tradeoff is shown on the right-hand-side of (16). The first term is a common-quantity effect, or a proportional effect: it measures the advantage of the larger population in terms of the quality of its population, ignoring differences in total population sizes. The second term in (16) is a commonquality effect, or a size effect: it measures the poverty disadvantage of the larger population in terms of the quantity of its population, setting proportional poverty constant across the two populations. These terms can take different signs, in which case total and average utilitarianism (and total and proportional poverty) may rank the populations differently. The size effect is always negative: for a given proportional poverty, the welfare importance of that poverty is larger for larger population sizes. But the proportional effect can certainly be positive - implying that, were it not for population size differences, poverty in the larger population would be lower.

The (17) term shows how the critical-level effect (always positive) may tilt the balance in favor of the proportional effect, or may also go against both the proportional and the size effects. The 
lower the value of $\alpha$, the more likely will the larger population tend to CLGU dominate the smaller one - this is true regardless of the contributions of the proportional and size effects. Moreover, even though a (negative) proportional effect may favor the smaller population (in addition to the negative size effect), it may still be that the larger population will CLGU dominate the smaller one. This would be because, in this case, the valuation of the quantity of lives is sufficiently large. In such a case, both the proportional and the total views would be reversed by CLGU.

\section{Robust ranges of critical levels}

The previous section addressed the difficulty of specifying a form for the CLGU $g$ function through an extension of relatively standard stochastic dominance techniques. Expressions (14) and (15) assume, however, a particular value for the critical level $\alpha$. As the literature provides little guidance on such a value, it is useful to extend the dominance techniques to assess over which values of $\alpha$ it is possible to rank the social value of two populations.

This we do by estimating the lower and upper bounds of ranges of critical levels over which a CLGU ranking can be made. ${ }^{9}$ The intuition is relatively simple. Assume that (14) holds for some value of $\alpha=\alpha_{0}$, and therefore that population $\mathbf{u}$ CLGU dominates population $\mathbf{v}$ at $\alpha_{0}$. Since (7) is invariant with respect to $\alpha$ and since (4) is decreasing with $\alpha$, (14) will also hold with higher values $\alpha>\alpha_{0}$. The right-hand side of (14) may not, however, hold at values of $\alpha$ lower than $\alpha_{0}$. The lowest value of $\alpha$ for which the right-hand side of (14) holds will set a lower bound to the range of critical levels for which the smaller population dominates the larger one. An analogous procedure is used for estimating an upper bound to the range of critical levels for which the larger population CLGU dominates the smaller one.

Let $\alpha_{s}$ and $\alpha^{s}$ then be defined respectively as follows:

$$
\alpha_{s}=\max \left\{\alpha \mid P^{s}\left(\mathbf{u}_{\alpha} ; z\right) \geq P^{s}(\mathbf{v} ; z) \text { for all } z\right\}
$$

and

$$
\alpha^{s}=\min \left\{\alpha \mid P^{s}\left(\mathbf{u}_{\alpha} ; z\right) \leq P^{s}(\mathbf{v} ; z) \text { for all } z\right\} .
$$

Defined as such, $\alpha_{s}$ is the maximum value of the critical level for which the larger population $\mathbf{v}$ dominates the smaller population $\mathbf{u}$ at $\operatorname{order} s$, whereas $\alpha^{s}$ is the minimum value of the critical level for which the population $\mathbf{u}$ dominates the population $\mathbf{v}$ at order $s$.

Let $F$ and $G$ be the cumulative distribution functions of $\mathbf{u}$ and $\mathbf{v}$ respectively, and let $F_{\alpha}(z):=$ $\frac{M}{N} F(z)+\frac{N-M}{N} I(\alpha \leq z)$ be the cumulative distribution function of $\mathbf{u}_{\alpha}$. The definitions (18) and (19) are illustrated graphically in Figures 1 and 2 for $s=1$. Figure 1 supposes that the larger

\footnotetext{
${ }^{9}$ The use of ranges of critical levels has also been suggested in Blackorby, Bossert, and Donaldson (1996) and Trannoy and Weymark (2009).
} 
population $\mathbf{v}$ dominates the lower population $\mathbf{u}$ for a range of poverty lines between 0 and $\alpha_{1}$. This is equivalent to saying that the absolute poverty incidence curve (which gives the absolute number of poor individuals; recall page 4) is lower in the larger population for all poverty lines between 0 and $\alpha_{1}$; this is also equivalent to finding that the cumulative distribution function $G$ lies under the cumulative distribution function $\frac{M}{N} F$. At $\alpha_{1}$, the two functions cross and $F_{\alpha_{1}}(z)$ also jumps. For all values of $\alpha$ lower than $\alpha_{1}, \mathbf{v}$ first-order dominates $\mathbf{u}$. Formally, this says that $\mathbf{u} \precsim \alpha 1 W \quad \mathbf{v}$ for all $\alpha \leq \alpha_{1}$. Note that $\mathbf{v}$ does not dominate $\mathbf{u}$ when the critical level is set to a value $\alpha$ greater than $\alpha_{1}$ (such as $\alpha_{2}$ ).

Figure 2 presents the symmetric case by supposing that the absolute of number of poor individuals is lower in the smaller population $\mathbf{u}$ than in the larger population $\mathbf{v}$ for a range of poverty lines between 0 and $\infty$. That is, however, not sufficient for the smaller population to CLGU dominate the larger one: we also require that $\alpha$ not be lower than $\alpha^{1}$. This is also equivalent to finding that the cumulative distribution function $G$ lies above the cumulative distribution function $F_{\alpha}$ for all $\alpha$ larger than $\alpha^{1}$. At $z=\alpha^{1}, G$ and $F_{\alpha}$ cross. Hence, $\mathbf{u}$ first-order dominates $\mathbf{v}$ for all critical levels set above $\alpha^{1}$. Formally, this means that $\mathbf{u} \succsim_{\alpha}^{1 W} \mathbf{v}$ for all $\alpha \geq \alpha^{1}$. Intuitively, the condition says that if a life worth living requires a relatively large income, then the additional lives are not sufficiently well-off to allow the larger population to dominate the smaller population, which does not have these additional low incomes.

\section{Application using PovcalNet data}

\subsection{Data description}

The global assessment of poverty and inequality has generated much interest in the academic literature. This interest is nicely reviewed in Anand and Segal (2008), which also discusses the important measurement and data issues that must be dealt with. Much of the recent academic debate has usefully focussed on several of these issues, and explored how their treatment affects the portrait of global poverty. This includes the choice of an indicator of well-being (typically consumption and/or income, scaled for economies of scale), adjusting for differences in prices and consumption behavior across time and space (using estimates of purchasing power parities and/or local consumption prices indices), the choice of a global poverty line, reliance on household survey data only (or on national accounts also), distinguishing between inequality and poverty and between absolute and relative poverty, and country weighting versus individual weighting of the poverty estimates. Some of the more recent contributions include Dikhanov and Ward (2001), Chen and Ravallion (2001), Milanovic (2002), Bourguignon and Morrisson (2002) Sala-i-Martin (2002), Chen and Ravallion (2004), Sala-i-Martin (2006), Chen and Ravallion (2010), and Deaton (2010). 
In this application, we mostly abstract from these important conceptual and measurement issues, except for a rather fundamental one, which has generated both interest and a sense of insatisfaction. Much of the recent evidence indeed reports opposite trends in how the number of the poor changes versus how the percentage of the poor varies across time, globally or locally - see for instance Dikhanov and Ward (2001), Bourguignon and Morrisson (2002), and Chen and Ravallion (2010) for important examples. This is indeed a troubling outcome, which inevitably leads to some confusion when it comes, for instance, to evaluating the poverty effect of development. More fundamentally, and as discussed above, neither of these absolute/relative statistics may in fact be sufficient to assess how global social welfare has been evolving from a social evaluation perspective.

The data we use come from the living standard household surveys carried out in most developing countries of the world during the last two decades. They are available on the World Bank's PovcalNet website in the form of grouped income distributions. We use the PovcalNet software tools to extract the grouped income distribution data for all available developing countries and then generate samples of individual-level microdata at the national level. ${ }^{10} \mathrm{~A}$ sample of 1,000 observations is generated for every dataset. ${ }^{11}$ A total of 173 countries (114 developing countries and 59 high-income countries) are thus included to estimate the world distribution of income/consumption (depending on the datasets) for 1990 and 2005. The Appendix presents the list of the high-income countries that are included, the developing countries that are excluded, and those developing countries for which we have only one survey.

The income (for short, although consumption is more frequently used) levels are expressed in yearly per capita 2005 PPP (purchasing power parity) US dollars. Whenever a dataset for a particular country is not available for 1990 or 2005, the nearest dataset for that country is used and the income data are extrapolated or interpolated to 1990 or 2005 using the relevant GDP growth estimates found in the World Development Indicators. ${ }^{12}$ We sometimes group countries into World-Bank-defined regions, identified as East Asia and Pacific (EAP), Europe and Central Asia (ECA), Latin America and the Caribbean (LAC), Middle East and North Africa (MENA), South Asia (SA) and Sub-Saharan Africa (SSA).

Using this, humanity's population size is estimated to be 5.3 billion in 1990 and 6.5 billion in 2005, and average income in the developing world is estimated to be $\$ 1,098$ in 1990 and $\$ 1,510$ in 2005. Estimated population sizes and average incomes by regions are shown in Table 1. The

\footnotetext{
${ }^{10}$ This is done by means of Shorrocks and Wan (2009)'s algorithm (which is programmed in the freely available Distributive Analysis Stata Program — see Araar and Duclos (2007)).

${ }^{11}$ Note that PovcalNet does not contain income data for high-income countries. High-income countries have nevertheless (nominally) been included in the analysis by setting their incomes to a value above the top $\alpha$ 's considered in this paper; this procedure, which essentially says that high-income countries do not matter for this paper's global CLGU analysis, would seem fine given the relatively low $\alpha$ 's (in all cases less than $\$ 4,000$ per capita per year, see for instance Table 2) used in this paper.

${ }^{12}$ See for instance http://databank.worldbank.org/ddp/home.do?Step=12\&id=4\&CNO=2. Whenever PovcalNet does not provide estimates of total population sizes, the information is obtained from http://www.indexmundi.com/
} 
ECA and LAC regions are those with the higher average incomes. The 1990-2005 period saw a reversal of the average income rankings of EAP and SSA (due in part to China's higher growth). SA has had an average income growth rate four times higher than that of SSA. Except for LAC, MENA and SSA, all regions in Table 1 have seen average income growth rates at least no lower than population growth rates. The developing world has seen increases in population size $(25 \%)$ and in average income (39\%) that are both higher than for the entire world $(22.5 \%$ and $30 \%$, respectively).

\subsection{Dominance of large over small}

Given this, can we tell whether global social welfare has increased between 1990 and 2005 ? A first answer is given by simply drawing the absolute poverty incidence curves $M P^{1}(\mathbf{u} ; z)$ and $N P^{1}(\mathbf{v} ; z)$ over a wide range of poverty lines. This is done on Figure 3 . The global absolute number of poor is lower in 2005 for all poverty lines up to $\$ 1,248$ (including at $\$ 456$, which corresponds to $\$ 1.25$ per day, and which is around the poverty line often used in international comparisons). Graphing the absolute number of the poor in the expanded 1990 population, $N P^{1}\left(\mathbf{u}_{\alpha} ; z\right)$, using a critical level set to $\alpha_{1}=\$ 1,248$ shows that there is first-order CLGU dominance of humanity in 2005 over humanity of 1990. Keeping in mind the earlier discussion, this also says that all first-order CLGU functions with critical levels no higher than $\$ 1,248$ will necessarily evaluate 2005 better than 1990.

This is a powerful result obtained simply from a straightforward inspection of the absolute poverty incidence curves. Table 2 repeats this exercise for the various regions and for various orders of CLGU dominance, namely, it provides estimates of the upper bounds of the ranges of critical levels for which 2005 dominates 1990 for more restricted classes of CLGU functions and for specific regions. We do not provide estimates for the ECA and MENA regions as there is no dominance relations between 1990 and 2005 for these regions. As seen with Figure 3, at any critical level lower than $\$ 1,248$, we can assert that global welfare has robustly increased between 1990 and 2005 in spite of the significant increase in world population size. Table 2 shows that the dominance of 2005 over 1990 is stronger for the EAP region and the entire world than it is for the LAC and the SSA regions. For instance, any critical level no greater than $\$ 2,229$ leads to first-order dominance of EAP in 2005 over EAP in 1990. To conclude that LAC in 2005 is better than in 1990 requires lower values of $\alpha$ : at first-order for instance, one would need to assume a critical level no greater than $\$ 817$.

As the order of dominance increases, the set of ordered distributions that can be ranked becomes larger. Also, once a lower-order CLGU dominance ranking between two distributions is established, higher-order dominance between these two distributions also holds up to a higher upper bound for the range of critical levels. This is visible in Table 2. 
An example of a social evaluation index in the class $W_{\alpha}^{1}$ is the critical-level utilitarian social evaluation index defined as

$$
W(\mathbf{u} ; \alpha)=\sum_{i=1}^{M}\left(u_{i}^{z}-\alpha^{z}\right)
$$

and

$$
W(\mathbf{v} ; \alpha)=\sum_{j=1}^{N}\left(v_{j}^{z}-\alpha^{z}\right) .
$$

The above notation $x^{z}$ says that $x$ is censored to $z$ if $x$ exceeds the censoring point $z$; otherwise, $x$ remains unchanged. Table 4 shows values of $W$ when the critical level is set to $\hat{\alpha}_{2}$ and when $\alpha$ is set above $\hat{\alpha}_{2}$. For some of these higher values of the critical level, the world in 1990 has greater social welfare than in 2005 . However, the usual social evaluation functions based on total and average utilitarianism unambiguously declare that the world in 2005 is better than in 1990 — for the developing world, the estimates for 1990 and 2005 are respectively of $\$ 4,557$ billion and $\$ 7,807$ billion for 1990 and 2005 in the case of total utilitarianism, and of \$1,098 and \$1,510 for average utilitarianism. The same applies for the entire world where the estimates for 1990 and 2005 are respectively of $\$ 36$ trillion and \$57 trillion for 1990 and 2005 in the case of total utilitarianism, and of $\$ 6,797$ and $\$ 8,826$ for average utilitarianism.

\subsection{Dominance of small over large}

It can also be that population size increases leads to a worse social evaluation. This is the case for some groups of countries in ECA and SSA, where we can estimate an $\alpha^{s}$ critical level value above which 1990 necessarily dominates 2005. To show this, we consider a group of 15 countries in ECA and 10 countries in SSA. In ECA, this includes Belarus, Bulgaria, the Czech Republic, Estonia, Hungary, Kazakhstan, the Kyrgyz Republic, Latvia, Macedonia, Moldova, Poland, Romania, Slovakia, Slovenia and Uzbekistan. The 10 SSA countries are made of Burundi, Comoros, the Congo Republic, Côte d'Ivoire, Ghana, Liberia, Mali, Niger, Rwanda and Tanzania.

The results are shown in Table 3: for instance, all first-order CLGU functions fall between 1990 and 2005 for the set of those countries and for any critical level $\alpha^{1}$ greater than $\$ 556$ this seems to be a relatively convincing case that social welfare can fall quite robustly in spite of a substantial increase in population size between 1990 and 2005. For all second-order CLGU functions (i.e., those that penalize inequality), this is true for any critical level $\alpha^{1}$ greater than $\$ 300$.

The dominance of 1990 over 2005 is less strong for the group of 10 SSA countries. No critical level makes all first-order CLGU functions to be larger in 1990 than in 2005. Restricting those functions to inequality-penalizing ones, however, makes 1990 better than 2005 for all critical levels larger than $\$ 481$. There is much stronger evidence that 1990 dominates 2005 for the group 
of 15 ECA countries; this is the case for all first-order CLGU functions and for all values of $\alpha$ larger than $\$ 135$. Hence, despite the finding that 2005 can reasonably be declared globally better than 1990, it is quite clear that social welfare in some groups of countries has deteriorated during the last decades.

This is also true for some individual countries. For most developing countries of the world, the Appendix provides the estimated values of the bounds of the ranges of critical levels for which 1990 dominates 2005, or the reverse. For some countries, such bounds cannot be estimated since a dominance relation does not exist. ${ }^{13}$ There are also 17 countries in the developing world that have a larger population in 1990 than in 2005; these are Albania, Armenia, Belarus, Bosnia, Bulgaria, Crotia, the Czech Republic, Estonia, Georgia, Hungary, Kazakhstan, Latvia, Lithuania, Moldova, Romania, Russia and Ukraine. Our estimates strongly suggest that more than half of these population-declining countries have also experienced a fall in social welfare between 1990 and 2005 .

\subsection{Comparison between CLGU and traditional approaches}

CLGU evaluations can also lead to social assessments that differ starkly from those of traditional approaches. Consider again the above group of selected ECA and SSA countries. As shown in Figure 4, the cumulative distribution function $\frac{M}{N} F$ lies everywhere under the the cumulative distribution function $G$. This says that the absolute number of poor people in 1990 is lower than the absolute number of poor people in 2005, suggesting that social welfare is higher in 1990. A similar conclusion applies when using a per capita approach: since $F$ is everywhere under $G$, the proportional number of poor people is lower in 1990, implying that 1990 is again better than 2005.

Suppose instead that we use CLGU for social evaluation purposes. For any critical level value greater than $\$ 556$, we also conclude that there has been a normatively robust decline in social welfare between 1990 and 2005 in parts of the ECA and SSA regions. But this is not the case for critical level values lower than $\$ 556$. Some of the first-order CLGU functions will indeed rank 2005 better if we assign levels lower than $\$ 556$ to the value of living. A similar conclusion applies to higher orders of dominance.

Figure 5 illustrates another situation that often occurs in SSA. As shown by Chen and Ravallion (2010)'s empirical results, the proportional poverty rate has fallen recently in SSA but the absolute number of the poor has gone up — due the relatively high rate of population growth in SSA. Let us consider eight such SSA countries, Benin, Burkina, Côte d'Ivoire, Ghana, Mali, Niger, Rwanda and Togo. The relevant curves are shown in Figure 5 over a range of $z \in[\$ 0, \$ 1,000]$.

\footnotetext{
${ }^{13}$ Altogether, this concerns 17 countries: Azerbaijan, Belarus, Macedonia and Russia in the ECA region; Guyana, Bolivia, Haiti, Honduras, Paraguay and Peru in the LAC region; Morroco in the MENA region; and Côte d'Ivoire, Ghana, Niger, Rwanda, and Tanzania in the SSA region.
} 
The proportional number of poor people has declined between $1990(F(z))$ and $2005(G(z))$ but the absolute number of poor people has increased (shown by the difference between $F(z) \cdot M / N$ and $G(z)$ ). Robust CLGU evaluations thus declare that 1990 is better than 2005 for any critical level higher than $\$ 1,000$ when incomes are censored at $\$ 1,000$. This is in accordance with the total poverty view that the situation of some countries in SSA has deteriorated over the last decades because there are more poor people. For a critical level value lower than $\$ 1,000$, however, welfare in these eight SSA countries can be shown to be higher in 2005 for some CLGU functions. This is because values of $\alpha \leq \$ 1,000$ would push the $P^{1}\left(\mathbf{u}_{\alpha} ; z\right)$ curve (given by $M / N F(z)+(1-M / N) I(\alpha \leq z)$ above $P^{1}(\mathbf{v} ; z)$ (given by $G(z)$ ) in Figure 5.

To see how CLGU valuations with critical levels below \$1,000 may clash, let the function $g$

in (1) be defined as $g(u)=\frac{u^{1-\varepsilon}}{1-\varepsilon}$ for any income $u$. (This is the well-known homothetic social utility function popularized by Kolm (1969) and Atkinson (1970).) $\varepsilon \geq 0$ provides the relative inequality aversion value. It is convenient to express social welfare in units of an equally distributed equivalent income (EDE), viz, the equally distributed level of income that gives the same level of social welfare. ${ }^{14}$ For $\varepsilon=0$ and $\alpha=\$ 600$, the social valuation of Benin, Burkina, Côte d'Ivoire, Ghana, Mali, Niger, Rwanda and Togo equals - \$5 billion for 1990 and -\$4 billion for 2005. Expressed in EDE units, this gives \$554 for 1990 and \$566 for 2005. Hence, social welfare has increased. For $\varepsilon=0.6$ and $\alpha=\$ 600$, the EDE estimate is $\$ 5,132$ and $\$ 5,094$ for 1990 and 2005 respectively, saying that 1990 is then better than 2005 . Incorporating aversion to inequality into utilitarian assessments of welfare gives relatively more importance to lower incomes and then gives preference to the earlier distribution (since it CLGU-dominates the larger 2005 population at lower $z$ ). Hence, for a critical level value below the lower bound of $\$ 1,000$, two different CLGU functions, both members of the class $W_{\alpha}^{1}$, can give opposite rankings to 1990 and 2005, depending on the degree of aversion to the inequality of individuals below that critical value.

\section{Conclusion}

This paper uses and extends an attractive but relatively little-known social evaluation approach to overcome the important flaws of traditional social assessments based on various forms of total

${ }^{14}$ The EDE for $\mathbf{u}$ and $\mathbf{v}$ are respectively defined as

$$
E D E_{\mathbf{u}}=\left\{\frac{1}{N} \sum_{i=1}^{M} u_{i}^{1-\varepsilon}+\left(\frac{N-M}{N}\right) \alpha^{1-\varepsilon}\right\}^{\frac{1}{1-\varepsilon}}
$$

and

$$
E D E_{\mathbf{v}}=\left\{\frac{1}{N} \sum_{j=1}^{N} v_{j}^{1-\varepsilon}\right\}^{\frac{1}{1-\varepsilon}}
$$


and average utilitarianism. It develops dominance relations for critical-level generalized utilitarianism that are sufficiently general to allow for different classes of attitudes to inequality in addition to different views on what critical level (the so-called value of living) should be used to make social evaluations. The CLGU dominance conditions are nicely tied to total and proportional poverty dominance. As in the traditional poverty and social welfare dominance literature, the conditions allow for tests of arbitrary orders, as well as (in a CLGU context) ranges of possible values for critical levels.

We apply this framework to data on the global distribution of income to assess whether global social welfare can be persuasively shown to have increased between 1990 and 2005. The answer is unambiguously yes if and only if we are willing to judge that lives with per capita yearly consumption of more than $\$ 1,248$ necessarily increase global social welfare. The same conclusion applies to Sub-Saharan Africa if and only if we are willing to make that same judgement for lives with any level of per capita yearly consumption above $\$ 147$. If not, we arrive at the opposite conclusion that global social welfare has decreased during this period for at least some of the admissible CLGU functions.

Whether these values of the critical levels are reasonable enough to make a firm judgement on the evolution of humanity is open to debate (see for instance Klugman, Rodríguez, and Choi (forthcoming)). For reference, note that Maddison (2010) uses 2005-PPP \$570-\$640 as a subsistence estimate of per capita income from 1 AD onwards, that Bairoch (1993) estimates a bare subsistence minimum of around 2005-PPP \$420, and that Becker, Philipson, and Soares (2005) calibrate the value of life expectancy using a level of income at which an individual would be indifferent between being dead and alive set to about 2005-PPP \$486 prices. This would support the view that global social welfare has globally and robustly increased between 1990 and 2005 (Table 2), that there are some CLGU functions that would declare total social welfare to have fallen in sub-Saharan Africa (Table 2), and that global social welfare has globally and robustly fallen between 1990 and 2005 for some countries in sub-Saharan Africa and Europe and Central Asia (Table 3).

We also examine how and why CLGU assessments and traditional total and per capita social evaluation approaches can conflict in theory, and do conflict in practice. Among other things, this rationalizes the important claim often made that the situation of some countries in the world may have deteriorated over the last decades because there are now more poor people than before, although their proportion in the total population may well have fallen.

The social evaluation questions addressed in the paper are at the heart of the optimal population size problem. ${ }^{15}$ They also have considerable policy relevance. For instance, the process of demographic transition (through a reduction of both fertility and mortality) in which a large part

\footnotetext{
${ }^{15}$ The notion of an optimal size can be seen as going back to the time of Plato, who quantified the optimal size of a state to be 5,040 individuals. See also Meade (1955), Mirrlees (1967), Dasgupta (1969), Lane (1975), Samuelson (1975), and Gigliotti (1983) for influential contributions.
} 
of humanity has recently engaged is often rationalized as one that maximizes per capita welfare under resource constraints. It is unlikely for developed countries that this process also maximizes social welfare in a CLGU perspective. For developed countries, a CLGU perspective can most likely provide a rationale for promoting policies that encourage fertility, such as the provision of relatively generous child benefits for families with more children.

Whether the current demographic transition is consistent with CLGU maximization in developing countries depends much on the value that is set for the critical level. A social planner would favor a population increase only if the additional lives enjoyed a level of income at least equal to that level. Indeed, if additional lives are below this level, policies could rightly favor enhanced family planning and birth control. Conversely, consider a policy change that reduces family planning and leads to new lives below the poverty line but above the critical level. The number and the fraction of poor will rise, but some of the CLGU functions may indicate this is a good thing. The paper's discussion and estimates of the ranges of robust critical levels for which global social welfare has been changing in one direction or in another can be instructive in those policy assessments.

Note finally that the paper does not address directly some very important aspects of the optimal population size problem. First, an important concern is that population growth may not be sustainable indefinitely, pointing to the question of when it may be optimal to take steps to limit it. Indeed, improvements in global social welfare over time, may, or may not, be sustainable, $i$. $e$., may or may not be followed by a collapse in the standard of living of future generations. The techniques developed in this paper are most suitable for making comparative static comparisons across steady-state populations of different sizes, which is an essential first step towards a full dynamic assessment. The comparison of the 1990 and 2005 world populations demonstrates that these comparisons are practical.

Second, the empirical application of the present paper ignores the value of health, longevity and education in the definition of welfare, making the analysis unresponsive to the pleas in the literature to go beyond income-based measures. The measurement framework is, however, perfectly capable of incorporating such other indicators of the value of human lives, a task that should be a natural step forward.

Third, the paper indicates the critical levels below which population growth is welfare-reducing and above which it is welfare-increasing. It does not take a stance on who should ultimately decide on the value of the critical level, what that value should precisely be, and what frame of reference (the nation-state or the world, for instance) should be appropriate for making normative comparisons of the value of societies. It may be, for instance, that incomes of $\$ 1,248$ may well be viewed as enhancing social welfare in a relatively poor country but not in a relatively rich one. 
Figure 1: Large $(G)$ dominates small $(F)$ : Poverty incidence curves with $\alpha=\alpha_{1}$ adjusted for differences in population sizes

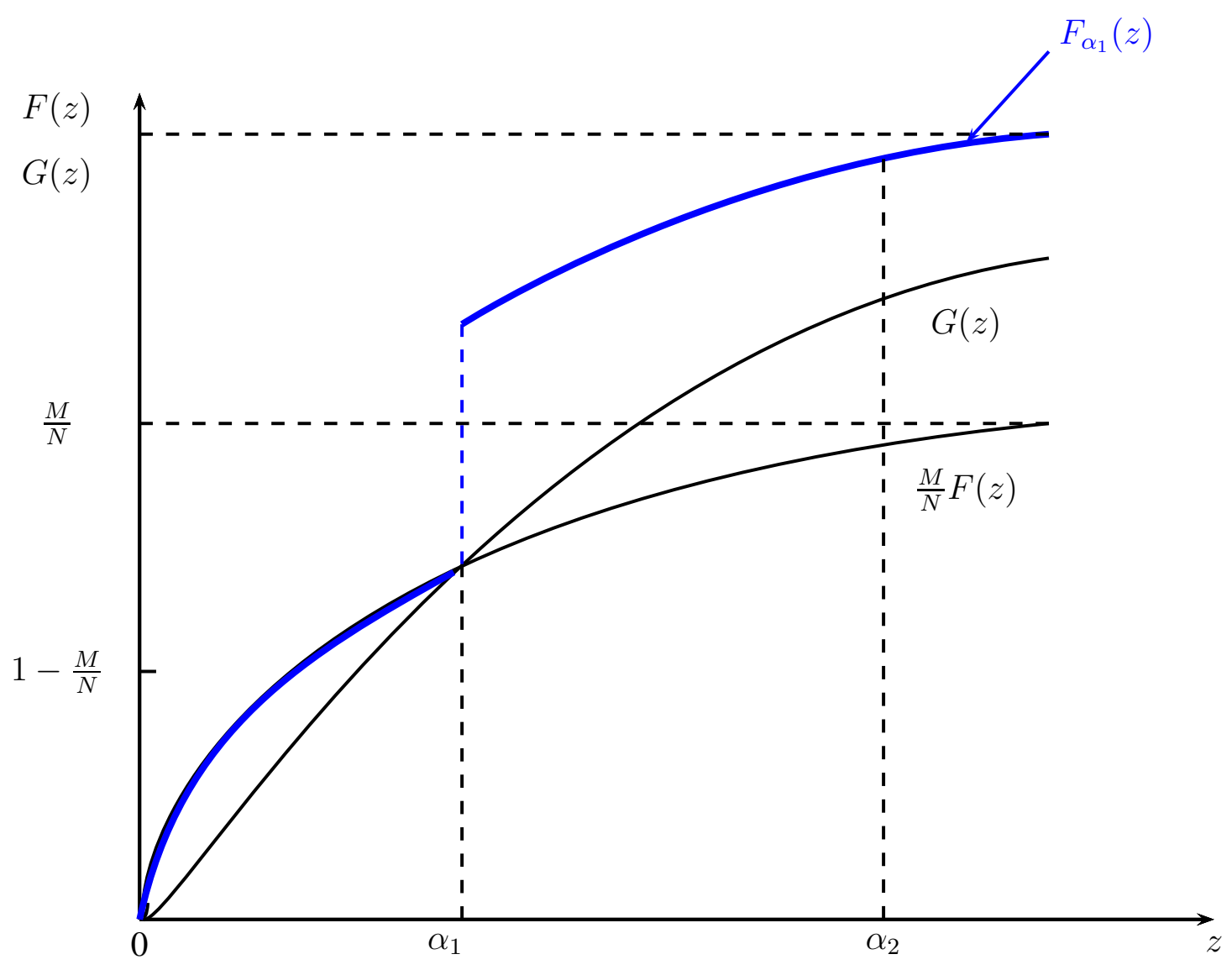


Figure 2: Small $(F)$ dominates large $(G)$ : Poverty incidence curves with $\alpha=\alpha^{1}$ adjusted for differences in population sizes

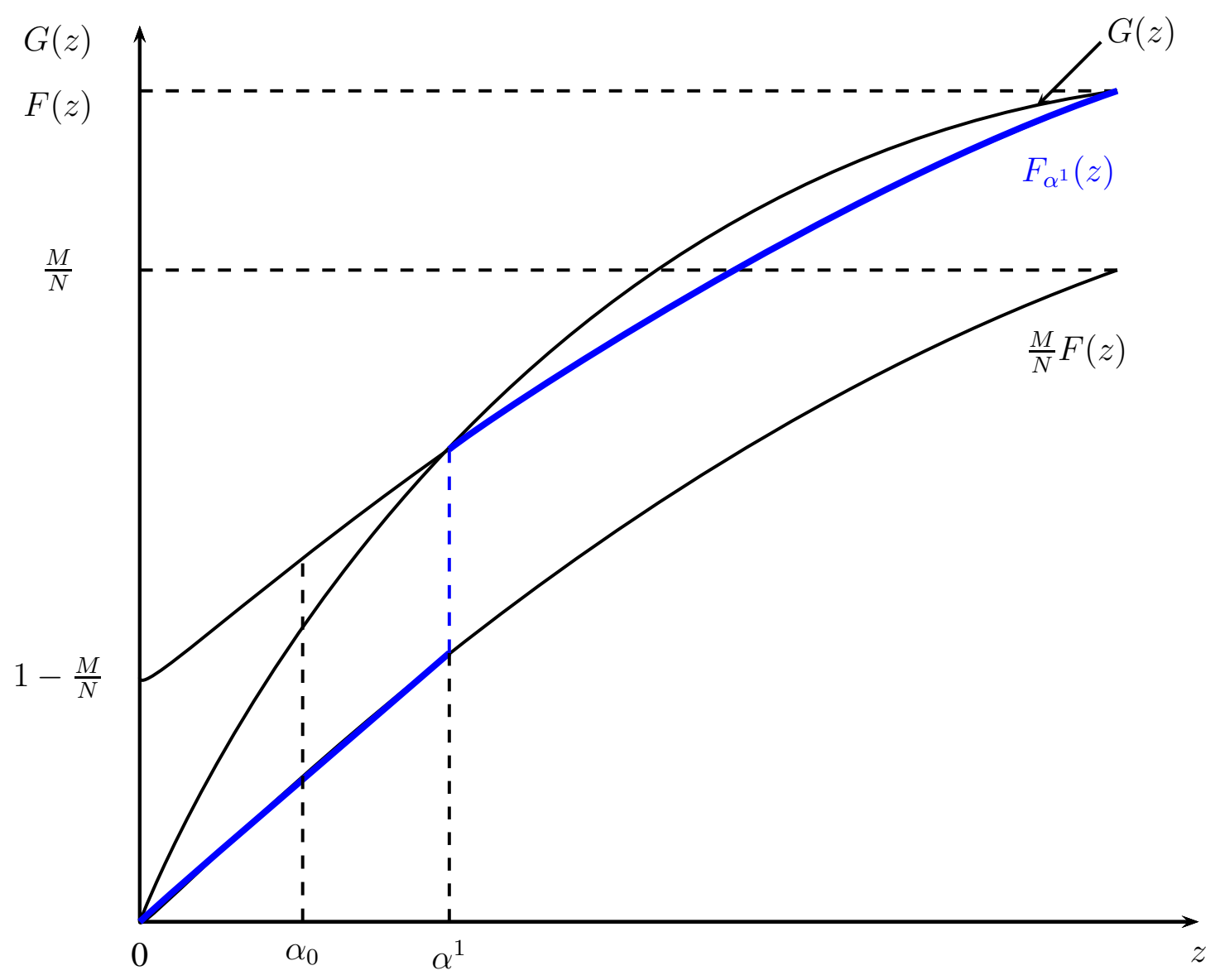


Figure 3: World in 2005 CLGU-dominates world in 1990, for all critical levels below $\$ 1,248$

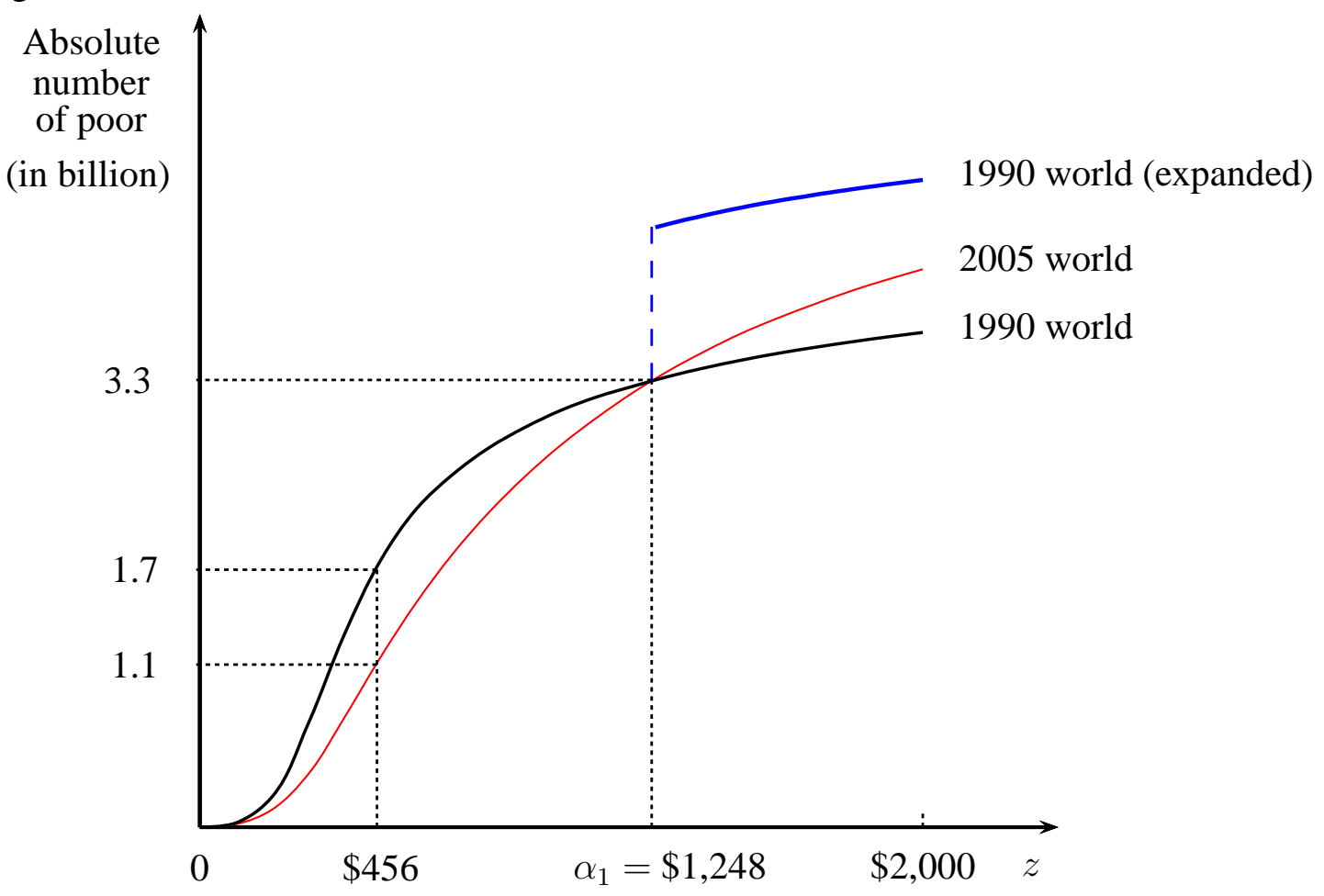


Figure 4: 1990 first-order CLGU dominates 2005 for a group of 15 ECA and 10 SSA countries, for all critical levels beyond $\$ 556$

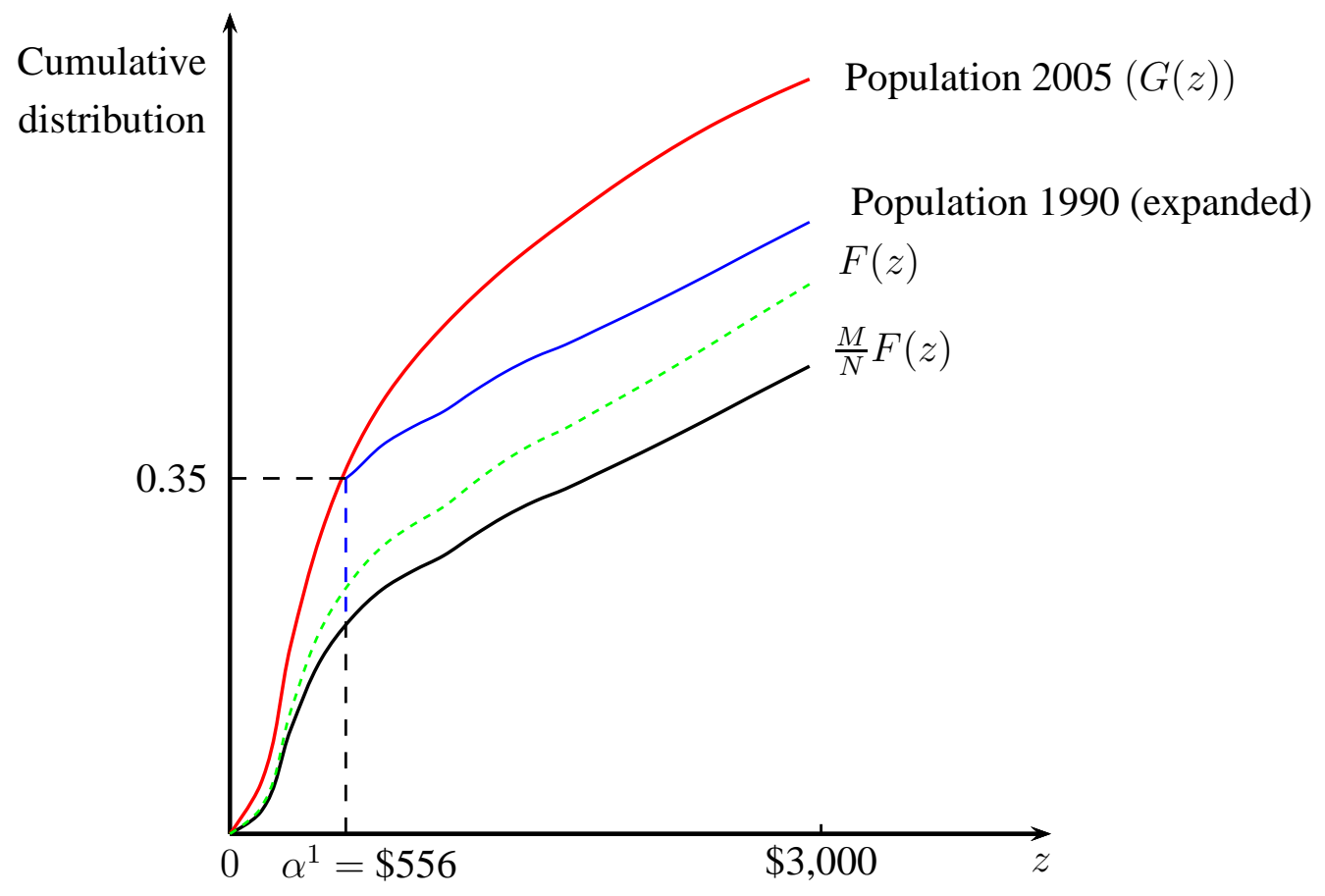

Figure 5: The increase in the absolute number of the poor leads to CLGU dominance of 1990 over 2005 in eight SSA countries

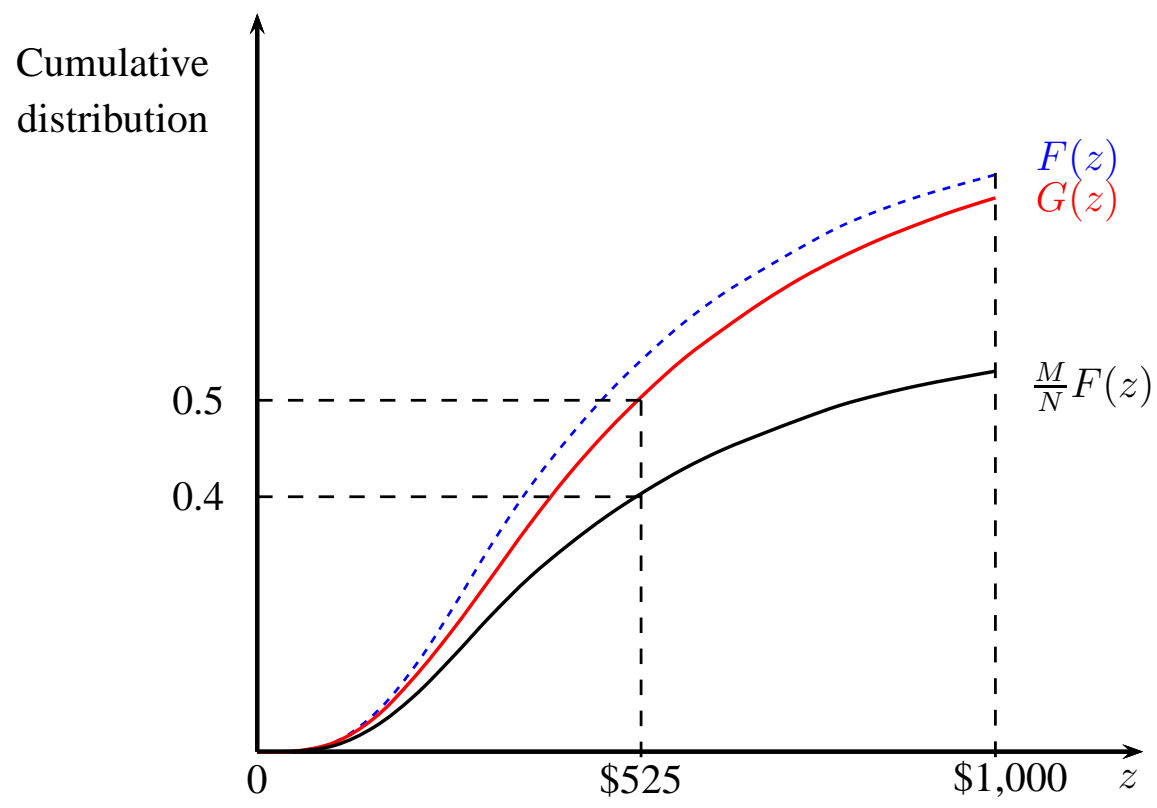


Table 1: Population sizes and average incomes by region, 2005 PPP USD

\begin{tabular}{|c|c|c|c|c|c|c|}
\hline \multirow[b]{2}{*}{ Regions } & \multirow{2}{*}{$\frac{\text { Population }}{1990}$} & \multirow{2}{*}{$\frac{\text { (in millions) }}{2005}$} & \multirow{2}{*}{$\begin{array}{c}\text { Growth in } \\
\text { population size }\end{array}$} & \multicolumn{2}{|c|}{ Average income } & \multirow{2}{*}{$\begin{array}{c}\text { Growth in } \\
\text { average income }\end{array}$} \\
\hline & & & & 1990 & 2005 & \\
\hline EAP & 1,540 & 1,810 & $18 \%$ & 580 & 1,520 & $162 \%$ \\
\hline ECA & 458 & 464 & $1 \%$ & 2,647 & 3,171 & $20 \%$ \\
\hline LAC & 393 & 497 & $26 \%$ & 2,899 & 3,185 & $10 \%$ \\
\hline MENA & 186 & 247 & $33 \%$ & 1,776 & 1,809 & $2 \%$ \\
\hline SA & 1,110 & 1,450 & $30 \%$ & 518 & 703 & $36 \%$ \\
\hline $\mathrm{SSA}$ & 463 & 695 & $50 \%$ & 799 & 757 & $-5 \%$ \\
\hline Developing world & 4,150 & 5,170 & $25 \%$ & 1,098 & 1,510 & $39 \%$ \\
\hline Entire world & $\overline{5,278}$ & $\overline{6,468}$ & $22.5 \%$ & 6,797 & 8,826 & $30 \%$ \\
\hline
\end{tabular}

Table 2: Estimates of the upper bounds of critical levels up to which 2005 dominates 1990, by region and order of CLGU dominance

\begin{tabular}{cccccc}
\hline \hline$s$ & EAP & LAC & SA & SSA & World \\
\hline & $\hat{\alpha}_{s}$ & $\hat{\alpha}_{s}$ & $\hat{\alpha}_{s}$ & $\hat{\alpha}_{s}$ & $\hat{\alpha}_{s}$ \\
$s=1$ & 2,229 & 817 & 620 & 147 & 1,248 \\
$s=2$ & 6,607 & 1,069 & 977 & 210 & 2,434 \\
$s=3$ & 11,581 & 1,356 & 1,378 & 278 & 3,710 \\
\hline \hline
\end{tabular}

Note: All critical levels are in 2005 PPP US dollars.

For the "World" category, see footnote 11 for the treatment of income from high-income countries.

Table 3: Estimates of the lower bounds of critical levels above which smaller populations dominate larger ones

\begin{tabular}{cccc}
\hline \hline$s$ & ECA (15) & SSA (10) & ECA \& SSA \\
\hline & $\hat{\alpha}^{s}$ & $\hat{\alpha}^{s}$ & $\hat{\alpha}^{s}$ \\
$s=1$ & 185 & - & 556 \\
$s=2$ & 135 & 481 & 300 \\
$s=3$ & 135 & 370 & 270 \\
\hline \hline
\end{tabular}

Note: All critical levels are in 2005 PPP US dollars. 
Table 4: Values of the utilitarian social evaluation index (in billion \$)

\begin{tabular}{|c|c|c|c|c|c|c|c|c|}
\hline \hline Year & \multicolumn{2}{|c|}{ EAP } & \multicolumn{2}{c|}{ LAC } & \multicolumn{2}{c|}{ SSA } & \multicolumn{2}{c|}{ World } \\
\hline \multirow{4}{*}{1990} & \multicolumn{2}{|c|}{$z=8,000$} & \multicolumn{2}{c|}{$z=1,800$} & \multicolumn{2}{c|}{$z=400$} & \multicolumn{2}{c|}{$z=3,000$} \\
\cline { 2 - 9 } & $\hat{\alpha}_{2}=6,607$ & $\alpha=6,700$ & $\hat{\alpha}_{2}=1,069$ & $\alpha=1,700$ & $\hat{\alpha}_{2}=210$ & $\alpha=360$ & $\hat{\alpha}_{2}=2,434$ & $\alpha=2,630$ \\
\cline { 2 - 9 } & $-9,278$ & $-9,421$ & 93 & -155 & 53 & -16 & $-6,503$ & $-7,794$ \\
2005 & $-9,259$ & $-9,428$ & 158 & -156 & 86 & -18 & $-6,323$ & $-7,336$ \\
\hline \hline
\end{tabular}




\section{References}

ANAND, S. AND P. SEGAL (2008): “What Do We Know about Global Income Inequality?" Journal of Economic Literature, 46, 57-94.

AraAR, A. AND J.-Y. DUClOS (2007): “DASP: Distributive Analysis Stata Package,” PEP, CIRPÉE, Université Laval.

Arrhenius, G. (2011): The Impossibility of a Satisfactory Population Ethics, World Scientific Publishing Company, Advanced Series on Mathematical Psychology.

ATKinson, A. (1970): "On the measurement of inequality," Journal of Economic Theory, 2, 244-263.

BAIRoch, P. (1993): Economics and World History: Myths and Paradoxes, Chicago: University of Chicago Press.

Becker, G., T. Philipson, And R. SoAres (2005): “The quantity and quality of life and the evolution of world inequality," American Economic Review, 95, 277-291.

Birdsall, N., A. Kelley, And W. Sinding (2003): Population Matters: Demographic Change, Economic Growth, and Poverty in the Developing World, Oxford University Press.

Blackorby, C., W. Bossert, And D. Donaldson (1996): "Quasi Ordering and Population Ethics," Social Choice and Welfare, 13, 129-150.

(2005): Populations Issues in Social Choice Theory, Welfare Economics and Ethics, New York: Cambridge University Press.

Blackorby, C. And D. Donaldson (1978): "Measures of Relative Equality and Their Meaning in Terms of Social Welfare," Journal of Economic Theory, 18, 59-80.

- (1984): "Social Criteria for Evaluating Population Change," Journal of Public Economics, 25, 13-33.

BourguignOn, F. AND C. MORRISSON (2002): "Inequality among World Citizens: 18201992," American Economic Review, 92, 727-44.

Broome, J. (1992a): Counting the Cost of Global Warming, White Horse, Cambridge. (1992b): “The Value of Living," Recherches Economiques de Louvain, 58, 125-142.

Burns, J. And H. HART (2000): "Bentham, Jeremy. A Comment on the Commentaries and A Fragment on Government," in The Works of Jeremy Bentham. Electronic edition, ed. by J. Burns, Charlottesville, Virginia, USA. 
Bussolo, M., R. De Hoyos, D. Medvedev, And D. van Der Mensbrugghe (2010): "Global Growth and Distribution: Are China and India Reshaping the World?" in Southern Engines of Global Growth, ed. by G. Wan and A. Santos-Paulino, Oxford University Press, 77-113.

Cassen, R. (1994): Population Policy: A New Consensus, Washington D.C., Overseas Development Council.

Chakravarty, S., R. Kanbur, And D. Mukherjee (2006): "Population Growth and Poverty Measurement," Social Choice Welfare, 26, 471-484.

Chen, S. And M. Ravallion (2001): "How Did the World's Poorest Fare in the 1990s?" Review of Income and Wealth, 47, 283-300.

_ (2004): “How Have the World's Poorest Fared Since the Early 1980s?” World Bank Research Observer, 19, 141-170.

- (2010): “The Developing World is Poorer than We Thought, But No Less Successful in the Fight Against Poverty," The Quarterly Journal of Economics, 125, 1577-1625.

Cockburn, J., J.-Y. Duclos, And A. ZabSOnRÉ (2011): "Is the value of humanity increasing? A critical-level enquiry," Working paper, FERDI.

Cogneau, D. And M. GRimm (2008): Journal of African Economies, 17, 688-728.

Cohen, J. E. (1995): How Many People Can the Earth Support?, New York: Routledge.

Cowen, T. (1989): "Normative Population Theory," Social Choice and Welfare, 6, 33-43.

Dasgupta, P. (1969): “On the Concept of Optimum Population," Review of Economic Studies, 36, 295-318.

(2010): “The Place of Nature in Economic Development," in Handbook of Development Economics, ed. by D. Rodrik and M. Rosenzweig, Amsterdam, The Netherlands: Oxford OX5 1GB, UK, vol. 5, 4977-5046.

DAVIES, J. AND M. HoY (1994): "The Normative Significance of Using Third-Degree Stochastic Dominance in Comparing Income Distributions," Journal of Economic Theory, 64, 520-30.

DeAton, A. (2010): "Price indexes, inequality, and the measurement of world poverty," American Economic Review, 100, 5-34.

DikHANOV, Y. AND M. WARD (2001): "Evolution of the Global Distribution of Income in 1970-99," Tech. rep., Instituto Brasileiro.

Eastin, J., R. Grundmann, And A. Prakash (2011): “The two limits debates: "Limits to Growth" and climate change," Futures, 43, 16-26. 
Edgeworth, F. Y. (1925): "Henry Sidgwick: The elements of Politics," in Papers Relating to Political Economy, ed. by F. Y. Edgeworth, London: Macmillan, vol. 3, 15-20.

Ehrlich, P. And A. Ehrlich (1990): The Population Explosion, New York: Routledge.

FishbuRn, P. AND R. Willig (1984): “Transfer Principles in Income Redistribution,” Journal of Public Economics, 25, 323-328.

Foster, J., J. Greer, And E. Thorbecke (1984): “A Class of Decomposable Poverty Measures," Econometrica, 52, 761-776.

Foster, J. And A. Shorrocks (1988): "Poverty Orderings and Welfare Dominance," Social Choice Welfare, 5, 179-98.

Gigliotti, G. A. (1983): “Total Utility, Overlapping Generations and Optimum Population," Review of Economic Studies, 50, 71-86.

Guillaumont, P. (1964): La pensée démo-économique de J. B. Say et de Sismondi, Paris: Éditions Cujas.

HASAN, M. S. (2010): “The long-run relationship between population and per capita income growth in China," Journal of Policy Modeling, 32, 355-372.

KAKWANI, N. (1980): “On a Class of Poverty Measures,” Econometrica, 48, 437-446.

KAnBuR, R. (2005): “Growth, Inequality and Poverty: Some Hard Questions," Journal of International Affairs, 58, 223-232.

Kanbur, R. And D. Mukherjee (2007): "Premature Mortality and Poverty Measurement," Bulletin of Economic Research, 59, 0307-3378.

KAVKA, G. S. (1982): “The Paradox of Future Individuals,” Philosophy and Public Affairs, $11,93-112$.

Klasen, S. And T. Nestmann (2006): "Population, Population Density and Technological Change," Journal of Population Economics, 19, 611-626.

Klasen, S. AND C. WINK (2003): ““"Missing Women”: Revisiting the Debate,” Feminist Economics, 9, 263-299.

Klugman, J., F. Rodríguez, And H.-J. CHOI (forthcoming): “The HDI 2010: new controversies, old critiques," Journal of Economic Inequality.

Kolm, S.-C. (1969): “The Optimal Production of Justice," in Public Economics, ed. by J. Margolis and S. Guitton, London: MacMillan.

- (1976): “Unequal Inequalities, I,” Journal of Economic Theory, 12, 416-42.

LANE, J. S. (1975): "A Synthesis of the Ramsey-Meade Problems when Population Change is Endogenous," Review of Economic Studies, 42, 57-66. 
Maddison, A. (2010): Tech. rep., Organisation for Economic Co-operation and Development, Paris.

MeAde, J. E. (1955): Trade and Welfare, Oxford University Press.

Milanovic, B. (2002): “True World Income Distribution, 1988 and 1993: First Calculation Based on Household Surveys Alone,” Economic Journal, 112, 51-92.

MiLl, J. S. (1859 (1962)): On Liberty, Glasgow: Fontana Press.

Mirrlees, J. A. (1967): "Optimum Growth when Technology is Changing," Review of Economic Studies, 34, 95-124.

MukHerJeE, D. (2008): "Poverty measures incorporating variable rate of alleviation due to population growth," Social Choice and Welfare, 31, 97-107.

Nerlove, M., A. Razin, And E. SAdKA (1986): "Endogenous population with public goods and Malthusian fixed resources: Efficiency or market failure," International Economic Review, 27, 601-609.

NG, Y.-K. (1986): "Social Criteria for Evaluating Population Change: An Alternative to Blackorby-Donaldson criterion," Journal of Public Economics, 29, 375-381.

PARFIT, D. (1984): Reasons and Persons, Oxford: Oxford University Press.

Pogge, T. (2005): "World Poverty and Human Rights," Ethics and International Affairs, $19,1-7$.

RAwls, J. (1971): A Theory of Justice, Cambridge: MA: Harvard University Press.

SALA-I-MARTIN, X. (2002): "The world distribution of income (estimated from individual country distribution)," Working paper 8933, NBER.

- (2006): “The World Distribution of Income: Falling Poverty and ... Convergence, Period," Quarterly Journal of Economics, 121, 351-397.

SAmuelson, P. A. (1975): “The Optimum Growth Rate for Population," International Economic Review, 16, 531-538.

SEN, A. (2001): "Many Faces of Gender Inequality,” Frontline, 18.

ShORROCKS, A. AND J. Foster (1987): “Transfer Sensitive Inequality Measures,” Review of Economic Studies, LIV, 485-497.

ShORROCKS, A. AND G. WAN (2009): "Ungrouping Income Distributions: Synthesising Samples for Inequality and Poverty Analysis," in Arguments for a Better World: Essays in Honor of Amartya Sen, Volume I: Ethics, Welfare, and Measurement, ed. by K. Basu and R. Kanbur, Oxford University Press, 414-435. 
Sumner, L. W. (1978): "Classical Utilitarianism and the Population Optimum," in Obligations to Future Generations, ed. by R. Sikora and B. Barry, Philadelphia: Temple University Press, 91-111.

Trannoy, A. And J. A. Weymark (2009): "Dominance Criteria for Critical-Level Generalized Utilitarianism," in Arguments for a Better World: Essays in Honor of Amartya Sen, ed. by K. Basu and R. Kanbur, Oxford: Oxford University Press, vol. I of Ethics, Welfare, and Measurement, 262-281.

United Nations (2011): “Commission on Population and Development: World demographic trends," Tech. Rep. E/CN.9/2011/6, New York. 


\section{Appendix}

\subsection{Critical level bounds for developing countries}

\begin{tabular}{|c|c|c|c|}
\hline Country & Larger population & Estimated bound & Change in welfare \\
\hline \multicolumn{4}{|l|}{ A } \\
\hline Albania & 1990 & $\hat{\alpha}^{1}=296$ & Improvement if $\alpha \geq \hat{\alpha}^{1}$ \\
\hline Algeria & 2005 & $\hat{\alpha}_{1}=2130$ & Improvement if $\alpha \geq \hat{\alpha}_{1}$ \\
\hline Angola & 2005 & $\hat{\alpha}_{1}=389$ & Improvement if $\alpha \geq \hat{\alpha}_{1}$ \\
\hline Armenia & 1990 & $\hat{\alpha}_{1}=185$ & Deterioration if $\alpha \leq \hat{\alpha}_{1}$ \\
\hline Azerbaijan & 2005 & $?$ & $?$ \\
\hline \multicolumn{4}{|l|}{$\mathrm{B}$} \\
\hline Bangladesh & 2005 & $\hat{\alpha}_{1}=519$ & Improvement if $\alpha \leq \hat{\alpha}_{1}$ \\
\hline Belarus & 1990 & $?$ & $?$ \\
\hline Benin & 2005 & $\hat{\alpha}_{1}=509$ & Improvement if $\alpha \leq \hat{\alpha}_{1}$ \\
\hline Bhutan & 2005 & $\hat{\alpha}_{1}=1646$ & Improvement if $\alpha \leq \hat{\alpha}_{1}$ \\
\hline Bolivia & 2005 & $?$ & $?$ \\
\hline Bosnia & 1990 & $\hat{\alpha}^{1}=333$ & Improvement if $\alpha \geq \hat{\alpha}^{1}$ \\
\hline Botswana & 2005 & $\hat{\alpha}_{1}=2270$ & Improvement if $\alpha \leq \hat{\alpha}_{1}$ \\
\hline Brazil & 2005 & $\hat{\alpha}_{1}=1352$ & Improvement if $\alpha \leq \hat{\alpha}_{1}$ \\
\hline Bulgaria & 1990 & $\hat{\alpha}_{1}=7828$ & Deterioration if $\alpha \leq \hat{\alpha}_{1}$ \\
\hline Burkina Faso & 2005 & $\hat{\alpha}_{1}=408$ & Improvement if $\alpha \leq \hat{\alpha}_{1}$ \\
\hline Burundi & 2005 & $\hat{\alpha}_{1}=125$ & Improvement if $\alpha \leq \hat{\alpha}_{1}$ \\
\hline \multicolumn{4}{|l|}{$\mathrm{C}$} \\
\hline Cambodia & 2005 & $\hat{\alpha}_{1}=598$ & Improvement if $\alpha \leq \hat{\alpha}_{1}$ \\
\hline Cameroon & 2005 & $\hat{\alpha}_{1}=985$ & Improvement if $\alpha \leq \hat{\alpha}_{1}$ \\
\hline Cape Verde & 2005 & $\hat{\alpha}_{1}=1550$ & Improvement if $\alpha \leq \hat{\alpha}_{1}$ \\
\hline Central African Rep. & 2005 & $\hat{\alpha}_{1}=407$ & Improvement if $\alpha \leq \hat{\alpha}_{1}$ \\
\hline Chad & 2005 & $\hat{\alpha}_{1}=652$ & Improvement if $\alpha \leq \hat{\alpha}_{1}$ \\
\hline Chile & 2005 & $\hat{\alpha}_{1}=3841$ & Improvement if $\alpha \leq \hat{\alpha}_{1}$ \\
\hline China & 2005 & $\hat{\alpha}_{1}=2481$ & Improvement if $\alpha \leq \hat{\alpha}_{1}$ \\
\hline Colombia & 2005 & $\hat{\alpha}^{1}=1481$ & Improvement if $\alpha \geq \hat{\alpha}^{1}$ \\
\hline Comoros & 2005 & $\hat{\alpha}_{1}=267$ & Improvement if $\alpha \leq \hat{\alpha}_{1}$ \\
\hline Congo & 2005 & $\hat{\alpha}_{1}=310$ & Improvement if $\alpha \leq \hat{\alpha}_{1}$ \\
\hline Congo Dem. Rep. & 2005 & $\hat{\alpha}^{1}=556$ & Deterioration if $\alpha \geq \hat{\alpha}^{1}$ \\
\hline Costa Rica & 2005 & $\hat{\alpha}_{1}=2216$ & Improvement if $\alpha \leq \hat{\alpha}_{1}$ \\
\hline Côte d'Ivoire & 2005 & $?$ & $?$ \\
\hline Crotia & 1990 & $\hat{\alpha}^{1}=4815$ & Improvement if $\alpha \geq \hat{\alpha}^{1}$ \\
\hline Czech Rep. & 1990 & $\hat{\alpha}_{1}=1856$ & Deterioration if $\alpha \leq \hat{\alpha}_{1}$ \\
\hline
\end{tabular}




\begin{tabular}{|c|c|c|c|}
\hline Country & Larger population & Estimated bound & Change in welfare \\
\hline \multicolumn{4}{|l|}{$\mathrm{D}, \mathrm{E}$} \\
\hline Djibouti & 2005 & $\hat{\alpha}^{1}=889$ & Deterioration if $\alpha \geq \hat{\alpha}^{1}$ \\
\hline Dominican Rep. & 2005 & $\hat{\alpha}_{1}=2179$ & Improvement if $\alpha \leq \hat{\alpha}_{1}$ \\
\hline Ecuador & 2005 & $\hat{\alpha}_{1}=390$ & Improvement if $\alpha \leq \hat{\alpha}_{1}$ \\
\hline Egypt & 2005 & $\hat{\alpha}_{1}=781$ & Improvement if $\alpha \leq \hat{\alpha}_{1}$ \\
\hline El Salvador & 2005 & $\hat{\alpha}_{1}=687$ & Improvement if $\alpha \leq \hat{\alpha}_{1}$ \\
\hline Estonia & 1990 & $\hat{\alpha}_{1}=5372$ & Deterioration if $\alpha \leq \hat{\alpha}_{1}$ \\
\hline Ethiopia & 2005 & $\hat{\alpha}_{1}=407$ & Improvement if $\alpha \leq \hat{\alpha}_{1}$ \\
\hline \multicolumn{4}{|l|}{$\overline{F, G}$} \\
\hline Gabon & 2005 & $\hat{\alpha}_{1}=799$ & Improvement if $\alpha \leq \hat{\alpha}_{1}$ \\
\hline Gambia & 2005 & $\hat{\alpha}_{1}=702$ & Improvement if $\alpha \leq \hat{\alpha}_{1}$ \\
\hline Georgia & 1990 & $\hat{\alpha}_{1}=211$ & Deterioration if $\alpha \leq \hat{\alpha}_{1}$ \\
\hline Ghana & 2005 & $?$ & $?$ \\
\hline Guatemala & 2005 & $\hat{\alpha}_{1}=1393$ & Improvement if $\alpha \leq \hat{\alpha}_{1}$ \\
\hline Guinea & 2005 & $\hat{\alpha}_{1}=399$ & Improvement if $\alpha \leq \hat{\alpha}_{1}$ \\
\hline Guinea Bissau & 2005 & $\hat{\alpha}_{1}=295$ & Improvement if $\alpha \leq \hat{\alpha}_{1}$ \\
\hline Guyana & 2005 & $?$ & $?$ \\
\hline \multicolumn{4}{|l|}{$\mathrm{H}, \mathrm{I}$} \\
\hline Haiti & 2005 & $?$ & $?$ \\
\hline Honduras & 2005 & $?$ & $?$ \\
\hline Hungary & 1990 & $\hat{\alpha}_{1}=7381$ & Deterioration if $\alpha \leq \hat{\alpha}_{1}$ \\
\hline India & 2005 & $\hat{\alpha}_{1}=574$ & Improvement if $\alpha \leq \hat{\alpha}_{1}$ \\
\hline Indonesia & 2005 & $\hat{\alpha}_{1}=945$ & Improvement if $\alpha \leq \hat{\alpha}_{1}$ \\
\hline Iran & 2005 & $\hat{\alpha}_{1}=920$ & Improvement if $\alpha \leq \hat{\alpha}_{1}$ \\
\hline \multicolumn{4}{|l|}{$\mathrm{J}, \mathrm{K}, \mathrm{L}$} \\
\hline Jaimaca & 2005 & $\hat{\alpha}_{1}=1201$ & Improvement if $\alpha \leq \hat{\alpha}_{1}$ \\
\hline Jordan & 2005 & $\hat{\alpha}_{1}=1200$ & Improvement if $\alpha \leq \hat{\alpha}_{1}$ \\
\hline Kazakhstan & 1990 & $\hat{\alpha}_{1}=6882$ & Deterioration if $\alpha \leq \hat{\alpha}_{1}$ \\
\hline kenya & 2005 & $\hat{\alpha}_{1}=650$ & Improvement if $\alpha \leq \hat{\alpha}_{1}$ \\
\hline Kyrgyzstan & 2005 & $\hat{\alpha}^{1}=444$ & Deterioration if $\alpha \geq \hat{\alpha}^{1}$ \\
\hline Lao republic & 2005 & $\hat{\alpha}_{1}=602$ & Improvement if $\alpha \leq \hat{\alpha}_{1}$ \\
\hline Latvia & 1990 & $\hat{\alpha}_{1}=8684.97$ & Deterioration if $\alpha \leq \hat{\alpha}_{1}$ \\
\hline Lesotho & 2005 & $\hat{\alpha}_{1}=736.29$ & Improvement if $\alpha \leq \hat{\alpha}_{1}$ \\
\hline Liberia & 2005 & $\hat{\alpha}^{1}=259.25$ & Deterioration if $\alpha \geq \hat{\alpha}^{1}$ \\
\hline Lithuania & 1990 & $\hat{\alpha}^{1}=1259.26$ & Improvement if $\alpha \geq \hat{\alpha}^{1}$ \\
\hline
\end{tabular}




\begin{tabular}{|c|c|c|c|}
\hline Country & Larger population & Estimated bound & Change in welfare \\
\hline \multicolumn{4}{|l|}{ 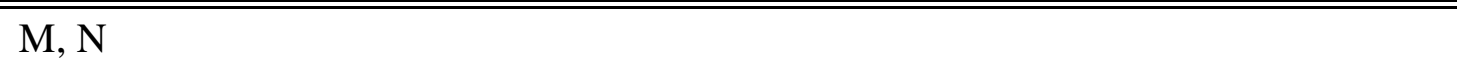 } \\
\hline Macedonia & 2005 & $?$ & $?$ \\
\hline Madagascar & 2005 & $\hat{\alpha}_{1}=194$ & Improvement if $\alpha \leq \hat{\alpha}_{1}$ \\
\hline Malawi & 2005 & $\hat{\alpha}_{1}=354$ & Improvement if $\alpha \leq \hat{\alpha}_{1}$ \\
\hline Malaysia & 2005 & $\hat{\alpha}_{1}=469$ & Improvement if $\alpha \leq \hat{\alpha}_{1}$ \\
\hline Mali & 2005 & $\hat{\alpha}^{1}=426$ & Deterioration if $\alpha \geq \hat{\alpha}^{1}$ \\
\hline Mauritania & 2005 & $\hat{\alpha}_{1}=947$ & Improvement if $\alpha \leq \hat{\alpha}_{1}$ \\
\hline Mexico & 2005 & $\hat{\alpha}_{1}=2703$ & Improvement if $\alpha \leq \hat{\alpha}_{1}$ \\
\hline Moldova Republic & 1990 & $\hat{\alpha}^{1}=519$ & Improvement if $\alpha \geq \hat{\alpha}^{1}$ \\
\hline Mongolia & 2005 & $\hat{\alpha}^{1}=504$ & Deterioration if $\alpha \geq \hat{\alpha}^{1}$ \\
\hline Morocco & 2005 & $?$ & $?$ \\
\hline Mozambique & 2005 & $\hat{\alpha}_{1}=375$ & Improvement if $\alpha \leq \hat{\alpha}_{1}$ \\
\hline Namibia & 2005 & $\hat{\alpha}_{1}=632$ & Improvement if $\alpha \leq \hat{\alpha}_{1}$ \\
\hline Nepal & 2005 & $\hat{\alpha}_{1}=489$ & Improvement if $\alpha \leq \hat{\alpha}_{1}$ \\
\hline Nicaragua & 2005 & $\hat{\alpha}_{1}=1057$ & Improvement if $\alpha \leq \hat{\alpha}_{1}$ \\
\hline Niger & 2005 & $?$ & $?$ \\
\hline Nigeria & 2005 & $\hat{\alpha}_{1}=73$ & Improvement if $\alpha \leq \hat{\alpha}_{1}$ \\
\hline \multicolumn{4}{|l|}{$\mathrm{P}, \mathrm{Q}, \mathrm{R}$} \\
\hline Pakistan & 2005 & $\hat{\alpha}_{1}=716$ & Improvement if $\alpha \leq \hat{\alpha}_{1}$ \\
\hline Panama & 2005 & $\hat{\alpha}_{1}=2030$ & Improvement if $\alpha \leq \hat{\alpha}_{1}$ \\
\hline Papua New Guinea & 2005 & $\hat{\alpha}_{1}=578$ & Improvement if $\alpha \leq \hat{\alpha}_{1}$ \\
\hline Paraguay & 2005 & $?$ & $?$ \\
\hline Peru & 2005 & $?$ & $?$ \\
\hline Philippines & 2005 & $\hat{\alpha}_{1}=213$ & Improvement if $\alpha \leq \hat{\alpha}_{1}$ \\
\hline Poland & 2005 & $\hat{\alpha}^{1}=537$ & Deterioration if $\alpha \geq \hat{\alpha}^{1}$ \\
\hline Romania & 1990 & $\hat{\alpha}_{1}=5874$ & Deterioration if $\alpha \leq \hat{\alpha}_{1}$ \\
\hline Russia & 1990 & $?$ & $?$ \\
\hline Rwanda & 2005 & $?$ & $?$ \\
\hline
\end{tabular}




\begin{tabular}{|c|c|c|c|}
\hline Country & Larger population & Estimated bound & Change in welfare \\
\hline \multicolumn{4}{|l|}{$\bar{S}$} \\
\hline Senegal & 2005 & $\hat{\alpha}_{1}=612$ & Improvement if $\alpha \leq \hat{\alpha}_{1}$ \\
\hline Sierra Leone & 2005 & $\hat{\alpha}_{1}=491$ & Improvement if $\alpha \leq \hat{\alpha}_{1}$ \\
\hline Slovakia & 2005 & $?$ & $?$ \\
\hline Slovenia & 2005 & $?$ & $?$ \\
\hline South Africa & 2005 & $\hat{\alpha}_{1}=157$ & Improvement if $\alpha \leq \hat{\alpha}_{1}$ \\
\hline Sri Lanka & 2005 & $\hat{\alpha}_{1}=1793$ & Improvement if $\alpha \leq \hat{\alpha}_{1}$ \\
\hline St. Lucia & 2005 & $\hat{\alpha}_{1}=1385$ & Improvement if $\alpha \leq \hat{\alpha}_{1}$ \\
\hline Suriname & 2005 & $\hat{\alpha}_{1}=1915$ & Improvement if $\alpha \leq \hat{\alpha}_{1}$ \\
\hline Swaziland & 2005 & $\hat{\alpha}_{1}=600$ & Improvement if $\alpha \leq \hat{\alpha}_{1}$ \\
\hline \multicolumn{4}{|l|}{$\mathrm{T}$} \\
\hline Tajikistan & 2005 & $\hat{\alpha}_{1}=1067$ & Improvement if $\alpha \leq \hat{\alpha}_{1}$ \\
\hline Tanzania & 2005 & $?$ & $?$ \\
\hline Thailand & 2005 & $\hat{\alpha}_{1}=2615$ & Improvement if $\alpha \leq \hat{\alpha}_{1}$ \\
\hline Timor-Leste & 2005 & $\hat{\alpha}_{1}=491$ & Improvement if $\alpha \leq \hat{\alpha}_{1}$ \\
\hline Togo & 2005 & $\hat{\alpha}_{1}=202$ & Improvement if $\alpha \leq \hat{\alpha}_{1}$ \\
\hline Trinidad and Tobago & 2005 & $\hat{\alpha}_{1}=8604$ & Improvement if $\alpha \leq \hat{\alpha}_{1}$ \\
\hline Tunisia & 2005 & $\hat{\alpha}_{1}=2473$ & Improvement if $\alpha \leq \hat{\alpha}_{1}$ \\
\hline Turkey & 2005 & $\hat{\alpha}_{1}=2750$ & Improvement if $\alpha \leq \hat{\alpha}_{1}$ \\
\hline Turkmenistan & 2005 & $\hat{\alpha}_{1}=3369$ & Improvement if $\alpha \leq \hat{\alpha}_{1}$ \\
\hline \multicolumn{4}{|l|}{$\mathrm{U}, \mathrm{V}, \mathrm{W}, \mathrm{X}, \mathrm{Y}, \mathrm{Z}$} \\
\hline Uganda & 2005 & $\hat{\alpha}_{1}=271$ & Improvement if $\alpha \leq \hat{\alpha}_{1}$ \\
\hline Ukraine & 1990 & $\hat{\alpha}^{1}=741$ & Improvement if $\alpha \geq \hat{\alpha}^{1}$ \\
\hline Uruguay & 2005 & $\hat{\alpha}_{1}=10550$ & Improvement if $\alpha \leq \hat{\alpha}_{1}$ \\
\hline Uzbekistan & 2005 & $\hat{\alpha}^{1}=365$ & Improvement if $\alpha \geq \hat{\alpha}^{1}$ \\
\hline Venezuela & 2005 & $\hat{\alpha}^{1}=1485$ & Deterioration if $\alpha \geq \hat{\alpha}^{1}$ \\
\hline Vietnam & 2005 & $\hat{\alpha}_{1}=1230$ & Improvement if $\alpha \leq \hat{\alpha}_{1}$ \\
\hline Yemen & 2005 & $\hat{\alpha}^{1}=859$ & Deterioration if $\alpha \geq \hat{\alpha}^{1}$ \\
\hline Zambia & 2005 & $\hat{\alpha}_{1}=196$ & Improvement if $\alpha \leq \hat{\alpha}_{1}$ \\
\hline
\end{tabular}




\subsection{Developing countries not included in PovcalNet data}

East Asia and Pacific

American Samoa

Myanmar

Fiji

Palau

Kiribati

Samoa

Korea Democratic Republic

Solomon Islands

Marshall Islands

Tonga

Micronesia Fed.

Vanuatu

Europe and Central Asia

Kosovo

Serbia

Montenegro

Latin America and the Caribbean

Argentina

Grenada

Belize

St. Kitts and Nevis

Cuba

St. Vincent and the Grenadines

Middle East and North Africa

Iraq

Syrian Arab Republic

Lebanon

West Bank and Gaza

Libya

South Asia

Afghanistan

Maldives

Sub-Saharan Africa

Eritrea

Seychelles

Mauritius

Somalia

Mayotte

Sudan

Sao Tomé and Principe

Zimbabwe

\subsection{Countries with only one survey}

Angola, Benin, Bhutan, Chad, Comoros, Congo Democratic Republic, Gabon, Haiti, Papua New Guinea, Namibia, Saint Lucia, Suriname and Togo. 


\subsection{High-income countries included in the global population counts}

$\begin{array}{lll}\text { Andorra } & \text { French Polynesia } & \text { Netherlands Antilles } \\ \text { Antigua and Barbuda } & \text { Germany } & \text { New Caledonia } \\ \text { Aruba } & \text { Greece } & \text { New Zealand } \\ \text { Australia } & \text { Greenland } & \text { Northern Mariana Islands } \\ \text { Austria } & \text { Guam } & \text { Norway } \\ \text { Bahamas } & \text { Hong Kong, China } & \text { Oman } \\ \text { Bahrain } & \text { Iceland } & \text { Portugal } \\ \text { Barbados } & \text { Ireland } & \text { Puerto Rico } \\ \text { Bermuda } & \text { Isle of Man } & \text { Qatar } \\ \text { Brunei Darussalam } & \text { Israel } & \text { San Marino } \\ \text { Belgium } & \text { Italy } & \text { Saudi Arabia } \\ \text { Canada } & \text { Japan } & \text { Singapore } \\ \text { Cayman Islands } & \text { Korea, Rep. } & \text { Spain } \\ \text { Channel Islands } & \text { Kuwait } & \text { Sweden } \\ \text { Cyprus } & \text { Liechtenstein } & \text { Switzerland } \\ \text { Denmark } & \text { Luxembourg } & \text { United Arab Emirates } \\ \text { Equatorial Guinea } & \text { Macao, China } & \text { United Kingdom } \\ \text { Faeroe Islands } & \text { Malta } & \text { United States } \\ \text { Finland } & \text { Monaco } & \text { Virgin Islands (U.S.) } \\ \text { France } & \text { Netherlands } & \\ & & \end{array}$

